\title{
Membranes, Chromatography and Membrane Chromatography. Separation Technologies for the Biopharm and Nutraceutical Era
}

\author{
Received in revised form 21 March 2005, accepted 11 March 2005 \\ Aniket V. Kale ${ }^{1}$ \& Munir Cheryan ${ }^{2 *}$ \\ ${ }^{1 \& 2}$ University of Illinois, Agricultural Bioprocess Laboratory, 1302 W. Pennsylvania Avenue, \\ Urbana, IL 61801, USA
}

\begin{abstract}
Membrane technology and process chromatography are widely used in the food, biopharmaceutical, nutraceutical and bioprocessing industries. Both techniques developed simultaneously and in parallel over the past few decades. The two technologies are complementary for the most part in terms of their advantages and disadvantages. Membrane chromatography integrates membranes and chromatography into one versatile technology. The resulting synergy has advantages and largely eliminates the disadvantages of the individual techniques, the most important being pore diffusion, thus leading to higher throughputs. This review compares the principles and applications of membranes, chromatography and membrane chromatography and their individual and combined roles in bioseparations.
\end{abstract}

Keywords : Chromatography, membrane chromatography, separation technologies

\subsection{INTRODUCTION}

Separations are indispensable in all chemical, biochemical, pharmaceutical and food industries. In almost all cases, the raw materials have to be prepared by separation of foreign material and contaminants and the final products have to be purified by separating the impurities and, for liquid processes, by removing the solvent. Processing food, biopharmaceuticals and bioproducts is more challenging due to the sensitivity of many biological components to extremes of heat, $\mathrm{pH}$ and shear. As shown in Table 1, components of a mixture can be separated if there is a difference in at least one physical property between them or between a component and the solvent in case of liquid mixtures. There are three major steps in a separation sequence, each of which may utilize one or more common unit operations:

(1) Recovery (initial solid-liquid separation): sedimentation, filtration, centrifugation.

(2) Concentration (removal of solvent): membranes, precipitation, adsorption, evaporation.

(3) Purification (removal of impurities): crystallization, chromatography, supercritical fluid extraction, membranes.

* Correspondence to: Munir Cheryan (e-mail: mcheryan@uiuc.edu) 
Table 1 Separating components in a mixture: Taking advantage of differences in physical properties

\begin{tabular}{ll}
\hline Property & \multicolumn{1}{c}{ Process } \\
\hline Density & Centrifugation \\
Diffusivity & Dialysis \\
Ionic charge & Ion exchange, electrodialysis \\
Size & Filtration, size exclusion chromatography, membranes \\
Solubility & Extraction with solvents or supercritical fluids; \\
& precipitation by heat, pH adjustment or addition of salts \\
Vapor pressure & Distillation \\
\hline
\end{tabular}

Membrane technology is used extensively in processing biobased products. As shown in Figure 1, membranes are used for separating and harvesting of enzymes and microorganisms, high-performance bioreactors for enzymatic and microbial conversion processes, tissue culture reactor systems, production of high-purity water, production of enriched nitrogen or oxygen using gas separation

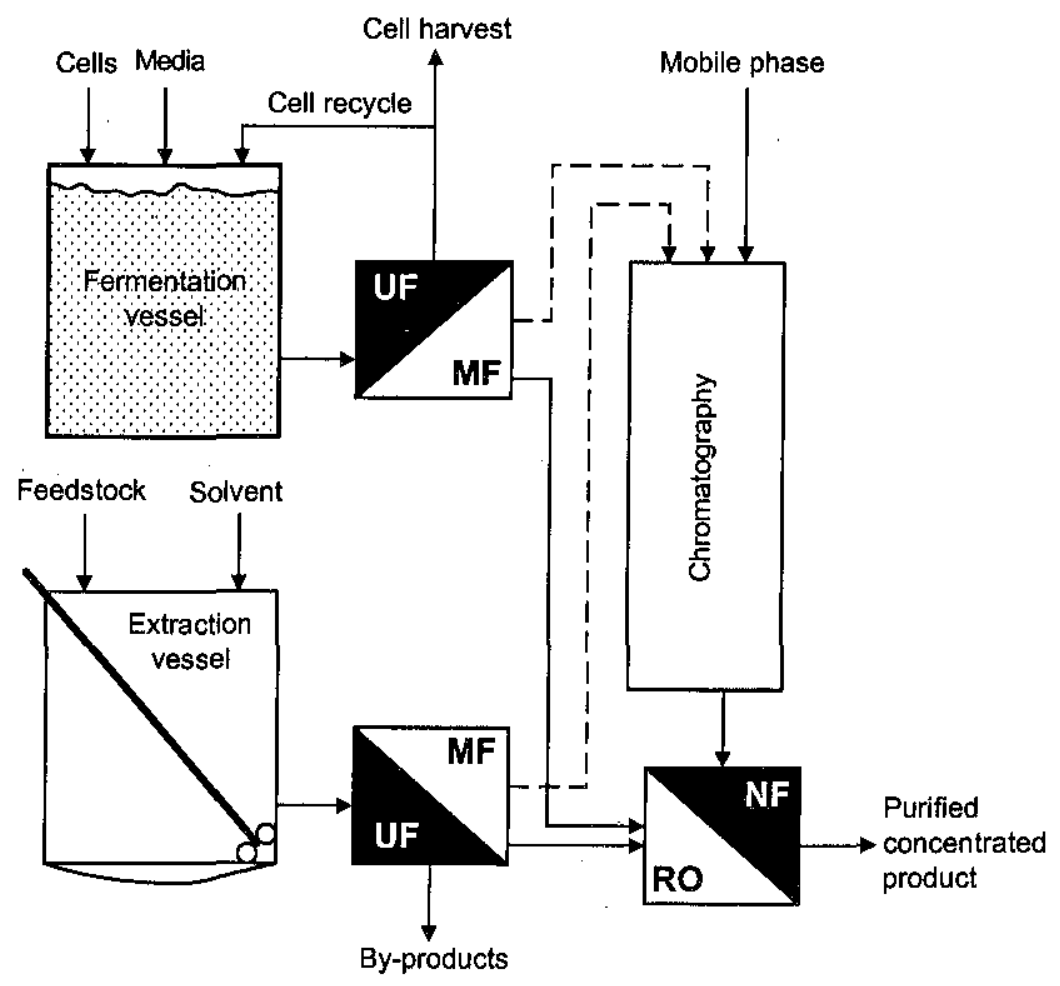

Figure 1 Typical process scheme for downstream processing of fermentation broths or extracts of natural products. Membrane technology such as MF and/or UF are used for cell separation and/or clarification. NF and/or RO are used for desalting and/or concentration of the final product. Chromatography is used for fine separations and final purification and/or concentration. The pure product stream eluting from the column may be concentrated using NF or RO 
membranes, desalting and concentration. If the objective is clarification of a fermentation broth or an extract, then the physical properties of the broth will determine the type of membrane and module configuration to be used [1]. Since membranes normally do not separate components with a molecular weight difference of less than 5-10 times, isolation and purification of the compound of interest will have to be done with a column technique such as chromatography. Membranes could be used prior to the column to purify or pre-concentrate the component and after the column to purify, desalt and concentrate the component.

There are also integrated membrane-based separation techniques such as pervaporation, which utilizes synthetic membranes to enhance separation factors of volatile components of a mixture by taking advantage of vapor pressure differences between them, and membrane chromatography which combines the selectivity of chromatography with the speed of membrane technology. This paper focuses on membrane chromatography and thus a brief introduction to the individual unit operations is necessary before discussing this relatively novel hybrid technology.

\subsection{MEMBRANE SEPARATIONS}

Membrane separations take advantage of the selectivity of semi-permeable membranes to separate components of a mixture primarily on the basis of size and, to a lesser extent, on shape and chemical composition. A membrane is essentially a filter that acts on a molecular, micro-and nano-scale, enriching certain components in a feed stream and depleting it of others. The chemical nature and physical properties of the membrane control which components are retained and which components permeate though the membrane. Figure 2 shows the major pressure-driven membrane processes. Reverse osmosis (RO) can be used to concentrate or dewater components in a solution, while

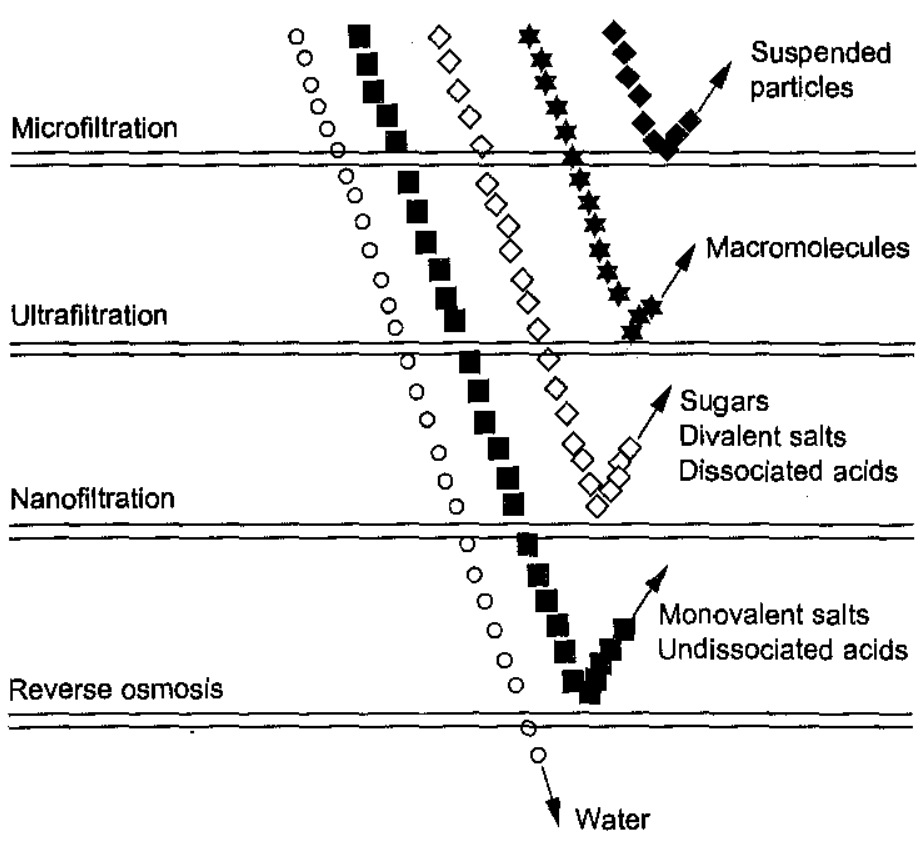

Figure 2 Classification and principles of membrane separations 
nanofiltration (NF) can be used to separate low molecular weight (MW) components from each other (e.g. sugar from salts). Large molecules (>1000 MW) can be separated from the smaller molecules by ultrafiltration (UF) while microfiltration (MF) is to clarify slurries or remove suspended matter. All these separation operations occur while simultaneously concentrating the retained components.

The most appealing feature of membrane technology is its simplicity. It involves only the bulk movement (i.e. pumping) of fluids using mechanical energy. In addition, membrane technology is a continuous molecular separation processes that does not involve a phase change or interphase mass transfer. The solvent (e.g. water) can be removed from a feed stream without a change in its state from liquid to vapor (as in evaporation) or liquid to solid (as in freeze concentration). Without the need for extremes of temperature, membranes can minimize damage to feed components resulting in products with better bioactivity and functional properties. Energy requirements are low compared to other dewatering and separation processes [2].

\subsection{Limitations}

A major limitation of membranes is its relatively low resolution capabilities for fine separations. This is a reflection of the pore size distribution of ideal and real membranes as shown in Figure 3 . The sharp distribution shown for the ideal membrane is never seen in practice. Most membranes have broad pore size distributions, sometimes covering more than one order of magnitude. Thus membranes are given "nominal" ratings such as "molecular weight cut-off" (MWCO) which refers to the molecular weight of a test solute which is $90 \%$ rejected by the membrane under standard conditions [1]. With proteins, MWCO cannot be directly compared to pore sizes measured by other techniques since proteins which differ by 10 times in MW may only differ by 3 times in size in their globular form. Fine fractionations are difficult or impossible on the basis of size alone. The general rule is that membranes can easily separate molecules that differ in molecular weight by ten times or if the hydrodynamic radius is different by three times.

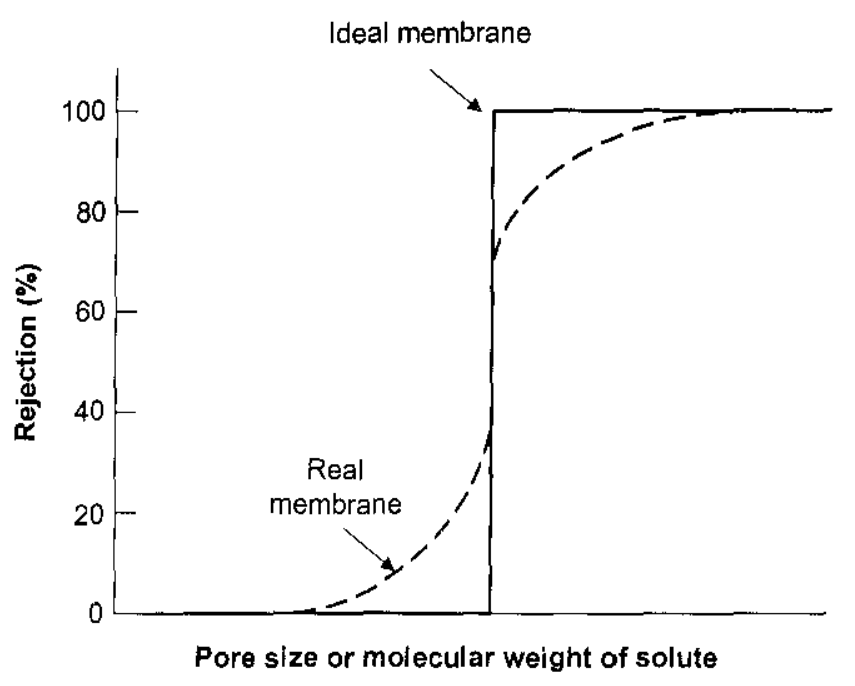

Figure 3 The limited resolution capabilities of membranes 


\subsection{Membrane Materials}

Over 200 materials have been commercially utilized for making membranes [1]. The first classification is usually whether the membrane material is polymeric or inorganic. The most widely-used membrane materials are shown in Table 2.

Table 2 Most commonly used membrane materials and their general applications

\begin{tabular}{ll}
\hline Polymeric membranes & Inorganic membranes \\
\hline Cellulose acetate & Alumina \\
Polyacrylonitrile & Carbon composite \\
Polyamide & Nickel \\
Polycarbonate & Silicon carbide \\
Polyethersulfone & Stainless steel \\
Polypropylene & Titania \\
Polysulfone & Zirconia \\
PTFE (polytetrafluoroethylene) & \\
Polyvinylidene fluoride & \\
Regenerated cellulose & \\
\hline
\end{tabular}

\subsection{Performance Parameters and Process Engineering of Membrane Systems}

The efficiency of a membrane separation is assessed by two parameters, flux and rejection. Flux is the volume of permeate per unit membrane area per unit time. It determines the capacity (throughput) and cost of a membrane system. Rejection $(R)$ is the measure of the separation capabilities of the membrane for a particular solute and is expressed in terms of solute concentration in the permeate $\left(C_{P}\right)$ and in the retentate $\left(C_{R}\right)$ :

$$
R=I-C_{P} / C_{R}
$$

These two parameters are affected by membrane properties such as pore size $\left(d_{p}\right)$, porosity of the membrane $(\varepsilon)$, thickness of the separating layer of the membrane or the "skin" $(\Delta x)$, by solution properties such as viscosity $(\mu)$, density $(\rho)$, diffusivity $(D)$ and osmotic pressure $(\pi)$, and by operating parameters such as pressure, temperature, flow rate and concentration. Figure 4 describes the relationship between flux $(J)$ and operating parameters. In the pressure-driven region:

$$
J=A P_{T}
$$

where $A$ is the membrane permeability coefficient, and $P_{T}$ is the transmembrane pressure, expressed as:

$$
P_{T}=\left(P_{F}-P_{P}\right)-\left(\pi_{F}-\pi_{P}\right)
$$

where the subscripts $F$ and $P$ refer to feed and permeate respectively. For UF and MF in the pressuredriven region, the osmotic pressure of the retained solutes is considered to be negligible and $A$ is written in terms of the Hagen-Poiseuille model: 


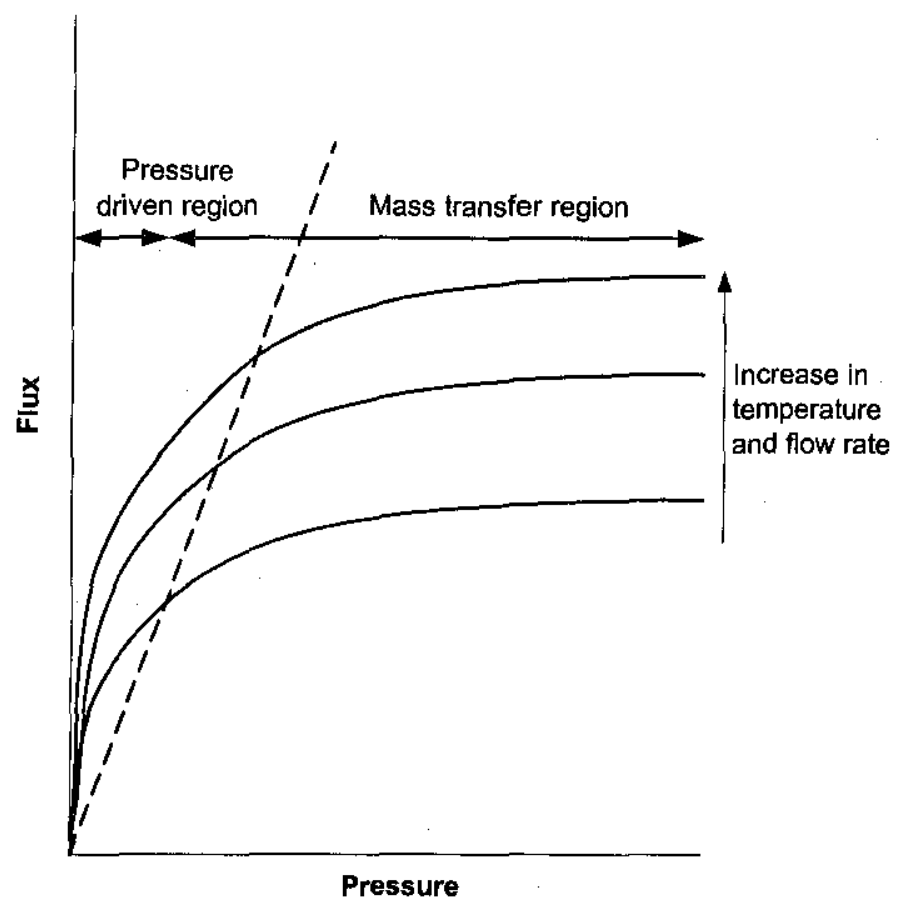

Figure 4 The effect of operating parameters on flux in a membrane process

$$
A=\frac{\varepsilon d_{p}^{2}}{32 \Delta x}
$$

In the mass-transfer controlled region, flux is independent of pressure and UF flux is modelled on the basis of film theory:

$$
J=k \ln \left(\frac{C_{G}}{C_{B}}\right)
$$

where $k$ is the mass transfer coefficient which is the ratio of the diffusion coefficient to the boundary layer thickness, $C_{G}$ is the limiting (gel) concentration, and $C_{B}$ is the bulk concentration of the retained solute(s). The mass transfer coefficient is a function of density, viscosity, membrane channel dimensions and cross-flow velocity $(v)$. In turbulent flow membrane modules, $k$ is a function of $v^{0.8-1.0}$. In laminar flow, $k$ is a function of $v^{0.33-0.5}$. For MF of colloidal or suspended particles, flux in the pressure-independent region is also influenced by shear in the direction of flow to a greater extent than that predicted by film theory and the transport coefficient is also a function of the solute particle size [1].

In reverse osmosis and nanofiltration, the membrane permeability coefficient $A$ in Equation (2) is dependent on several additional factors depending on the mechanism of transport of solutes and solvent. Models used to describe this transport are classified as irreversible thermodynamic (IT) models or physical-chemical-structural models. The irreversible thermodynamic transport models correlate rejection with measurable macroscopic properties. However, they do not explain the flow and separation mechanisms. Some of the popular models using this approach are the KedemKatchalsky model, Pusch's linear IT model and the Bilayer IT model [2]. The physical-chemical- 


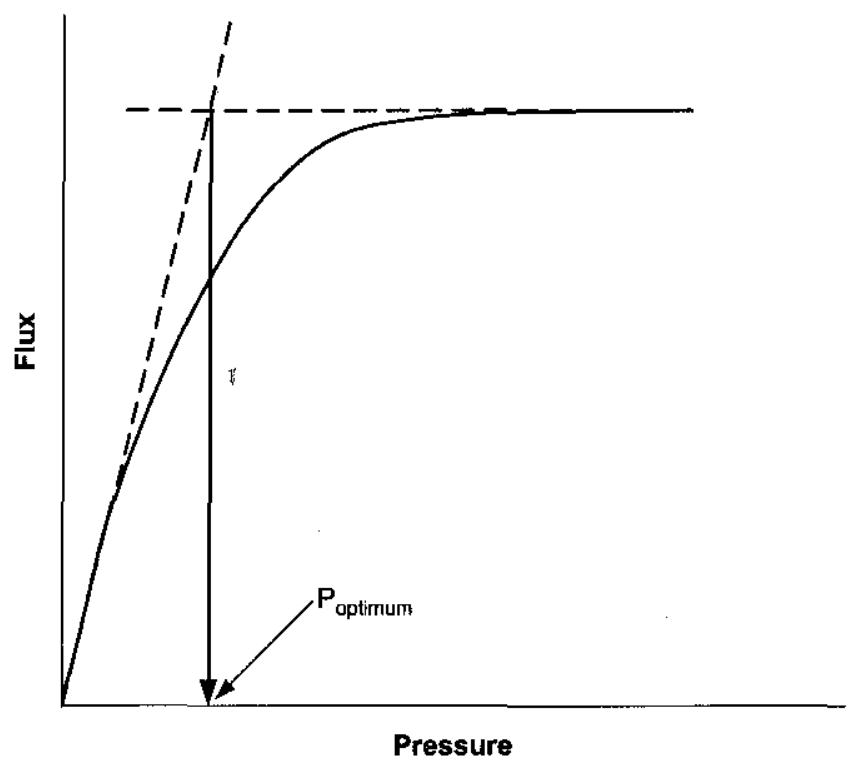

Figure 5 Determining the optimum pressure in a membrane process

structural models assume a mechanism for transport and then correlate rejection behavior with structural properties (porosity, tortuosity, pore size) and physicochemical properties (diffusivity, solubility). These models use a combination of three parallel transport mechanisms: diffusion due to pressure gradient, diffusion due to concentration gradient and hydrodynamic flow through pores. The models using this approach are the solution-diffusion model, pore flow model, frictional transport model and preferential-sorption capillary model [2].

The optimum operating pressure would be the pressure at which the driving force changes from pressure-controlled to mass transfer-controlled as shown in Figure 5.

\subsection{Membrane Equipment}

The modules in industrial scale processes may be classified into four main types. These have been compared in Table 3 and discussed in detail by $[1,2]$.

Table 3 Comparison of membrane module configurations

\begin{tabular}{lllll}
\hline & Plate and frame & Tubular & Hollow fiber & Spiral wound \\
\hline Flux & Good & Highest & Good & Lowest \\
Capital and operating costs & Moderate & High & Moderate & Lowest \\
Energy consumption & High & Moderate & Moderate & Lowest \\
Surface to volume ratio & Moderate & Lowest & High & High \\
Flow & $\begin{array}{l}\text { Laminar or turbulent } \\
\text { depending on design }\end{array}$ & Turbulent & Laminar & Turbulent \\
& & & \\
\hline
\end{tabular}




\subsection{Membrane Fouling and Cleaning}

Typical foulants may be categorized into four types, inorganic (salts, acids, bases), organic (proteins, lipids, polysaccharides, humectants), microbial (endotoxins, viruses) and colloidal. The most commonly used cleaning chemicals are caustic $(\mathrm{NaOH})$, oxidants/sanitizers $\left(\mathrm{NaOCl}, \mathrm{H}_{2} \mathrm{O}_{2}\right)$, acids (citric acid, nitric acid), chelating agents (citric acid, EDTA), and non-ionic surfactants (Tween 20). The success of a cleaning regime is determined by how much of the original water flux had been regained.

\subsection{CHROMATOGRAPHIC SEPARATIONS}

Chromatography is a physical method of separation based on differential retention of individual components of a liquid mixture by a solid support. Separation occurs by partitioning the target compound between the flowing fluid and the solid. The solid (stationary) phase with the appropriate physical and chemical properties is placed in a column (Figure 6). After equilibration with a buffer or solvent (\#1), a certain volume of the feed solution containing the components to be separated is fed into the column (\#2). This is followed by passing the mobile phase through the column, which elutes the individual components in a manner that depends on their physicochemical interactions with the stationary phase (\#3). The mobile phase can be a gas in the case of gas chromatography (GC), aqueous or organic liquid as in liquid chromatography (LC) or a supercritical fluid (SFC). The components elute from the end of the column at different times as separate bands (\#4). The column may then have to be regenerated (\#5).

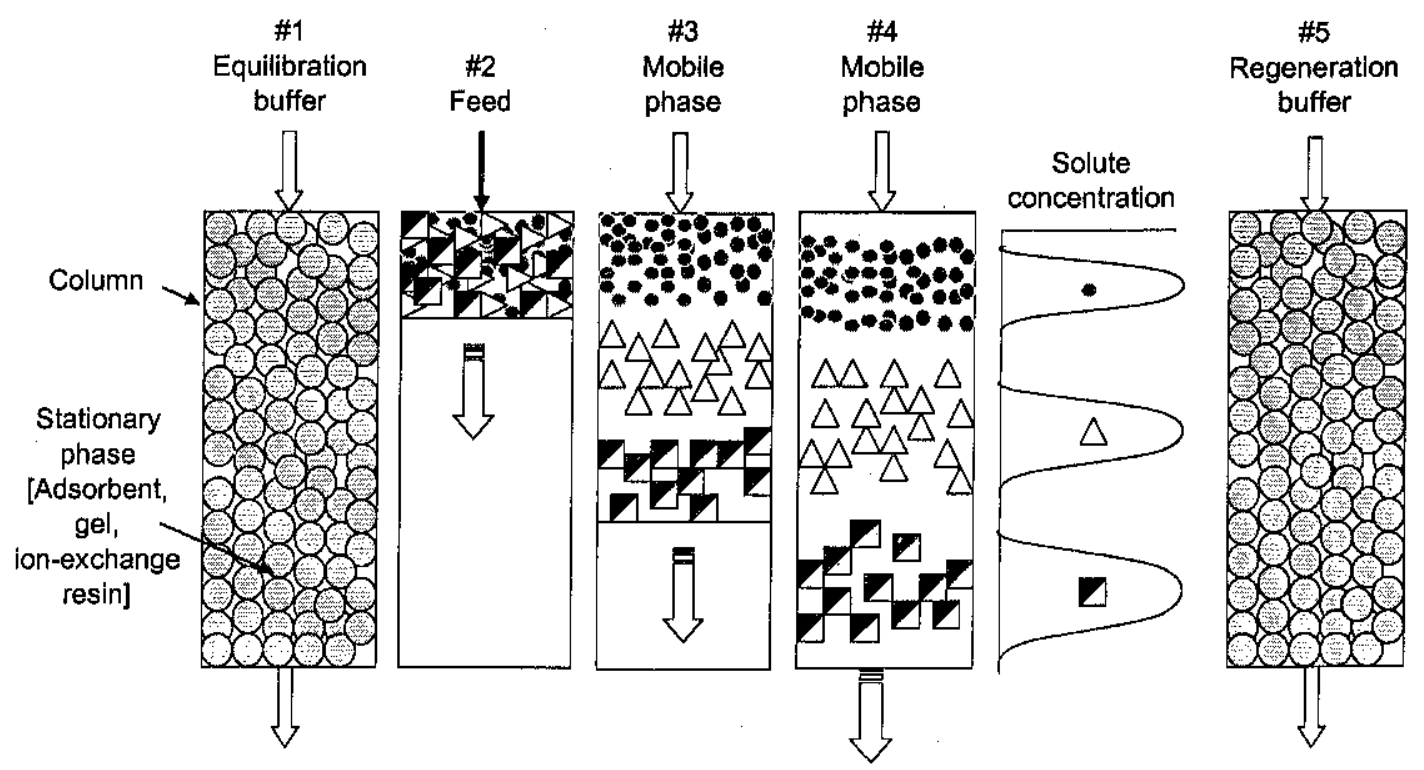

Figure 6 Principle of chromatographic separation 
Separation occurs as a result of two opposing forces. The mobile phase provides the driving force that moves the solutes in the direction of flow. Opposing this is a resistance brought on by interaction of the solute with the solid phase. Solute molecules move alternately between the solid phase and the mobile phase, being moved down the length of the column by the flowing action of the mobile phase, while being retarded by the solute's interaction with the active sites on the solid phase or adsorbent. Different solutes will interact with solid phase to different extents, with those that are strongly attracted spending more time in the column. The solute may spread out in a band or zone during passage through the column, the width of which depends on hydrodynamics (the extent of non-ideal flow patterns, axial dispersion), diffusional limitations (boundary-layer mass transfer, intrapore diffusion) and poor kinetics due to slow binding rates between the solute and the active site on the particle [3].

Differential migration of the solutes is a result of the specific interactions between the solute, solid phase and the mobile phase, which in turn is responsible for the "selectivity" of the system. The different types of interactions that can be utilized are shown in Figure 7. Charge interactions are the basis of ion-exchange chromatography (IEC), which is the most widely used industrial chromatographic process used today. Compared to other chromatographic methods discussed below, IEC can have high resolution between the components, high capacity and high throughputs. It is most effective in the early stages of a downstream process where large volumes are processed.

In IEC, charged substances are separated via column materials that carry an opposite charge. The ionic groups of exchanger columns are covalently bound to the gel matrix and are compensated by small concentrations of counter ions, which are present in the buffer. When a sample is added to the column, an exchange with the weakly bound counter ions takes place. This is comparatively easier in proteins since there are several multivalant anions and cations. Under strongly acidic pH conditions, all proteins are present as cations as a result of suppression of the dissociation of the carboxyl group and protonation of the amino group. At highly basic conditions, they are present as anions because the amino group is a free base and the carboxyl group is dissociated. Due to the net charge of the proteins, it is easily possible to bind them to a corresponding charged stationary phase [4]. The size of the sample volume in ion exchange chromatography is of secondary importance as long as the initial solvent is of low eluting strength so as not to allow any separation to occur during loading. When the gradient is started by the addition of stronger eluting mobile phase, the sample components begin their separation. Thus the solutes can be obtained in a more concentrated form.

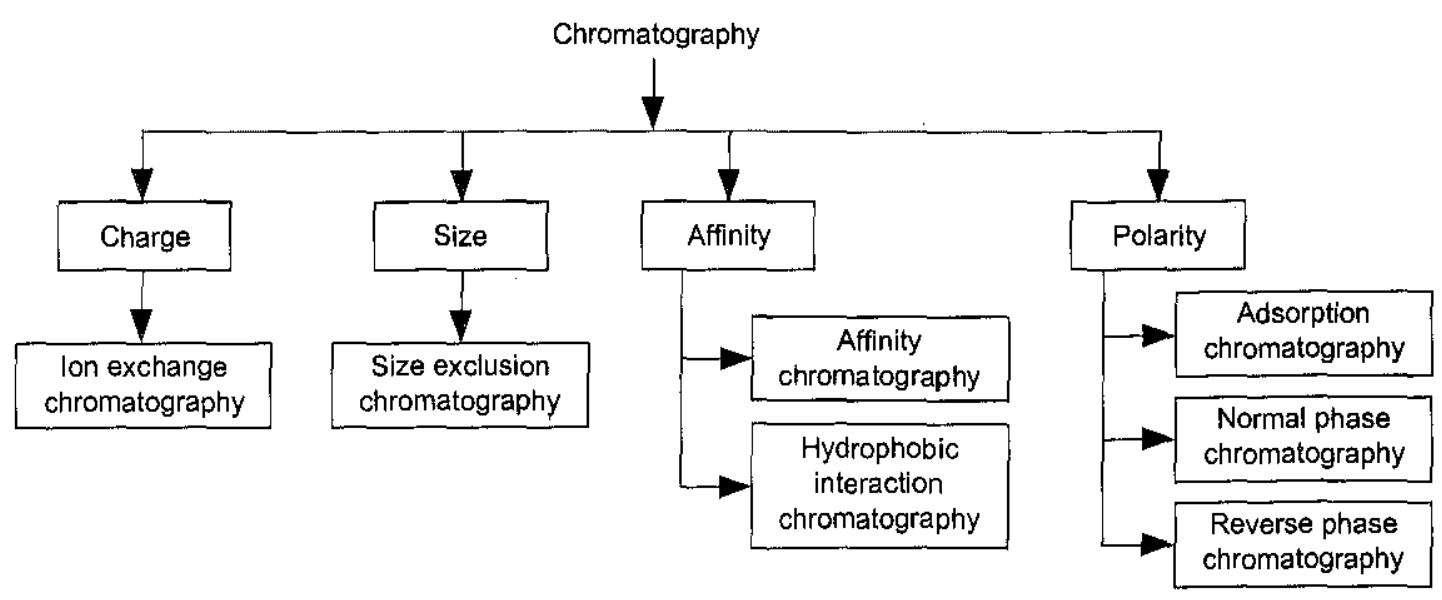

Figure 7 Classification of chromatographic processes based on the physical property utilized for separation 
Separations can be improved by a change in the gradient slope. If the proteins do not bind to the column under the selected conditions, the concentration and/or the $\mathrm{pH}$ of the starting buffer should be changed. Additional changes in selectivity can be made by choosing different buffer salts since each buffer solvates the ion exchanger and the sample components uniquely [4].

Size Exclusion Chromatography (SEC) is based on differences in solute size and shape and is commonly referred to as gel permeation. The stationary phase (gel matrix) has pores of a defined diameter that excludes larger molecules which remain in the void volume of the gel. Molecules that are smaller than the pore will enter the pore and be retarded. During elution, the excluded molecules such as proteins will exit with the eluent in the first retention volume [5]. In this respect, SEC is similar to ultrafiltration which is also designed to separate large molecules from small molecules. For this reason, SEC has been suggested as an alternative to UF and diafiltration for removal of salt and low MW impurities and for buffer exchange.

Resolution is good for buffer exchange and desalting, and moderate for fractionation which is best done in the later stages of purification, where lower loadings can be used. Capacity and throughput rates are relatively low for proteins.

Hydrophobic Interaction Chromatography (HIC) is based on van der Waals interactions. This technique takes advantage of clusters of nonpolar, hydrophobic amino acids that tend to be found on surfaces of proteins to facilitate preferential adsorption to the appropriate adsorbent and their subsequent elution with high salt concentrations [5]. Resolution, capacity and throughput rates are good, and it may be especially good at high ionic strengths, e.g., after ion exchange or salt precipitation.

Affinity Chromatography is also a widely-used industrial method to purify proteins, enzymes, monoclonal antibodies, hormones, vaccines and other compounds present in very low concentrations [6]. A ligand is attached to the active site of a solid support and the solute of interest interacts specifically with the ligand during passage through the column. The solute is then eluted with a mobile phase that may be of varying composition to improve separation. Common ligands are reactive dyes such as Cibacron Blue F3GA, Protein A, Protein G, histidine and highly specific antibodies. Resolution, capacity and throughput rates are good.

Reverse Phase Chromatography, Normal Phase Chromatography and adsorption are based on specific polarity differences between solutes and the solid support. Reverse phase could also generate hazardous solvents wastes [7].

\subsection{Limitations}

The major limitations of industrial chromatography are: (a) Relatively low throughput rates, (b) High pressure drops, and (c) Intra-pore diffusion. These three factors are inter-related. As shown in Figure 8, porous chromatography beads have active sites (that interact with the solute of interest) located on the surface and within the pores. In order for the solute to interact with all the binding sites, it has to first diffuse through a stagnant layer of solvent that surrounds the particle, then diffuse into the pore, followed by binding to the site. During elution, the reverse has to occur before the product elutes from the column. In most cases, pore diffusion is the limiting step. Thus the flow rate through the column has to be limited in order to allow these three steps to occur.

In addition, exceeding the optimum flow rate can lead to a loss of resolution (defined later) and high pressure drop in the column which can damage the support. Flow rate also affects the capacity of a chromatography support, which is measured by breakthrough curves (Figure 9). Breakthrough is defined as the point at which the solute appears in the eluent [8]. The breakthrough curve relates the exit concentration profile to the mass of solute or eluent volume or residence time. In ideal cases, a pulse of solute injected into a column with the feed should emerge from the column as a single pulse. In reality, there is broadening of the solute concentration at the exit due to mass transfer 


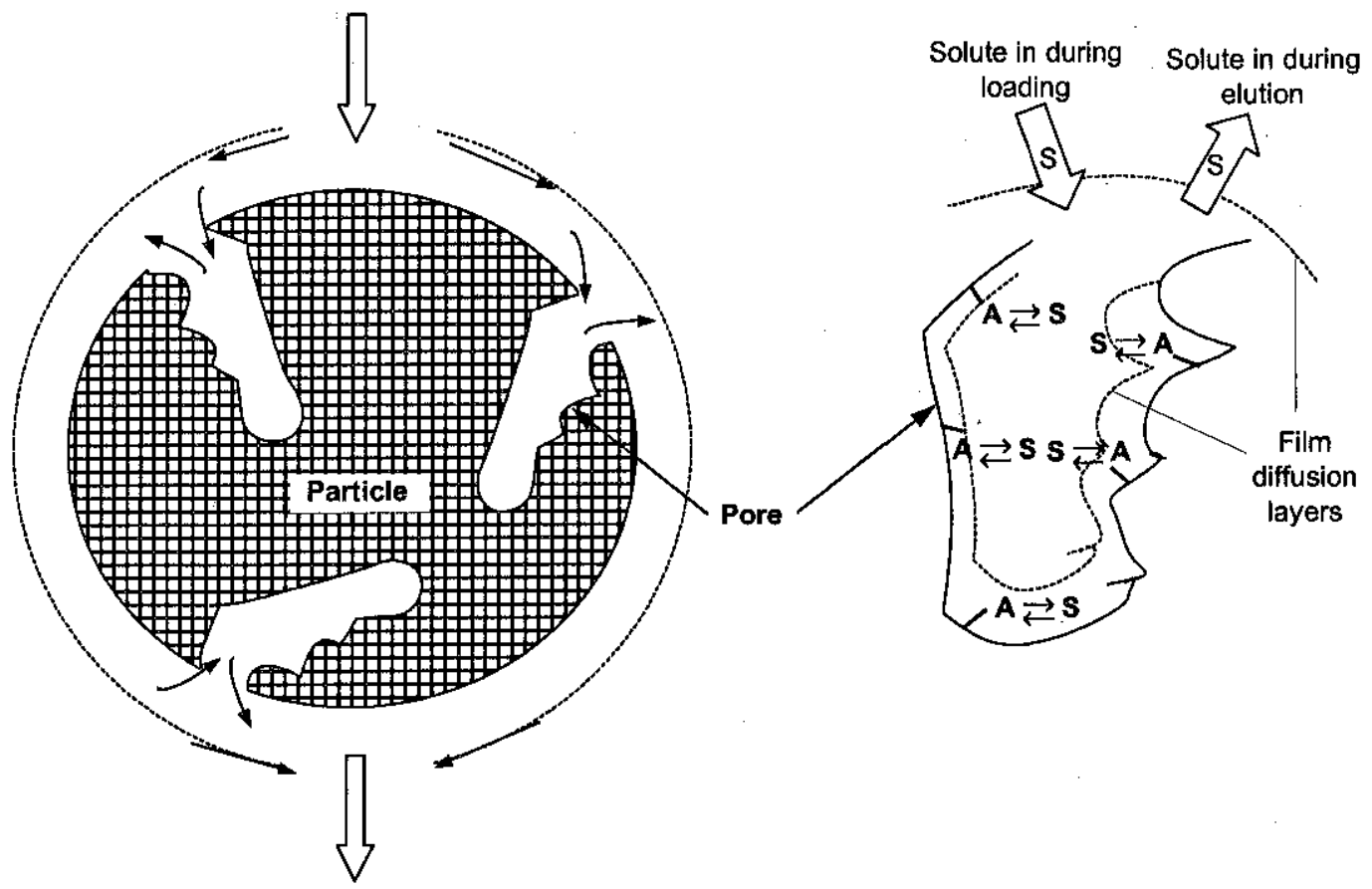

Figure 8 Principle of particle-based chromatographic processes. S is the solute to be separated and A is the active on the particle which may be ion exchanger groups such as sulfonic acid or quarternary amines for IEC, or ligands such as Protein A or Protein G for affinity chromatography

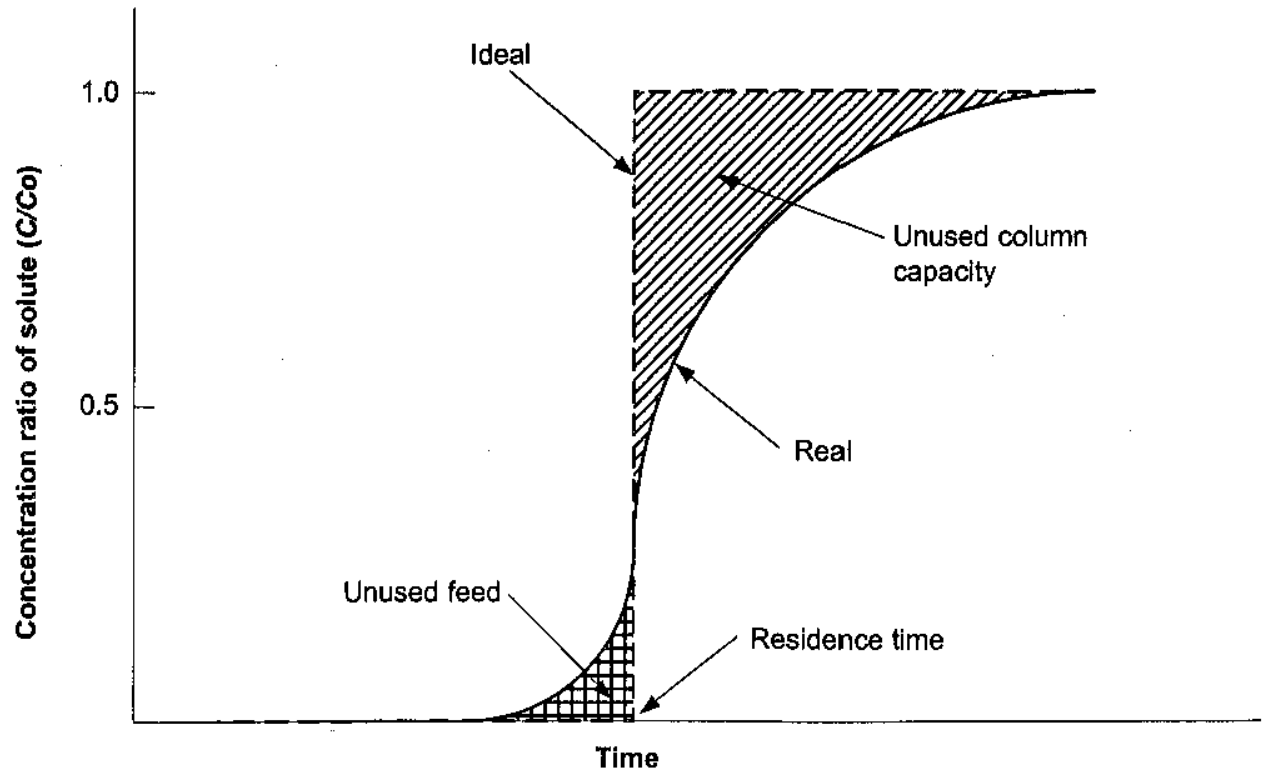

Figure 9 Breakthrough curve in chromatography. $C$ is the concentration of solute at time $t$ and $C o$ is the initial concentration of solute 
effects, non-uniformity of flow, hydrodynamic instabilities and slow binding kinetics. A non-ideal and broad breakthrough curve could mean that some of the feed is wasted and/or that some of the column has not been utilized.

\subsection{Chromatography Materials}

Based on the matrix material, chromatography media may be segregated into synthetic polymeric (e.g., polystyrene divinyl benzene), natural or biopolymeric (e.g., dextran) and ceramic matrices (e.g., silica, alumina). Depending on the physical property utilized, specific functional groups or ligands are attached to the solid matrix, or the matrix is chemically treated to result in the desired properties. In IEC, the exchanger groups are differentiated as basic/anionic (positively charged) or acidic/cationic (negatively charged). Anion exchangers are used to separate negatively charged molecules whereas cation exchangers are used to separate positively charged molecules. They in turn can be divided into those with weakly basic or acidic character and strongly basic or acidic character. With strongly basic or acidic materials, all functional groups are always present in ionized form. For example, the quaternary amino groups $\left(\mathrm{R}_{3} \mathrm{~N}^{+}-\right)$used in anion exchangers are positively charged with a pK value of $\sim 14$, while the sulfonic acid groups $\left(-\mathrm{SO}_{3}{ }^{-}\right)$in cation exchangers are negative with a pK value below 1 . The most common ion exchanger groups are summarized in Table 4 with their abbreviations and $\mathrm{pK}$ values.

Table 4 Common exchanger groups associated with the chromatography media

\begin{tabular}{llll}
\hline Functional group & pK Value & Characteristic & Description \\
\hline TMAE Group & $>13$ & strongly basic & Trimethylammoniumethyl- \\
DEAE- Group & 11 & weakly basic & Diethylaminoethyl- \\
DMAE- Group & $8-9$ & weakly basic & Dimethylaminoethyl- \\
$\mathrm{COO}^{-}$Group & 4.5 & weakly acidic & Carboxy- \\
$\mathrm{SO}_{3}^{-}$Group & $<1$ & strongly acidic & Sulfoisobutyl- \\
$\mathrm{SE}^{-}$Group & $<1$ & strongly acidic & Sulfoethyl- \\
\hline
\end{tabular}

There are also weakly basic types (pK between 8 and 11) consisting of secondary and tertiary amino functional groups and weakly acidic types (pK between 4 and 6) which are carboxyl functional groups. Thus, a weakly basic exchanger should only be used at $\mathrm{pH}$ values below 8.5 while weakly acidic exchangers only at $\mathrm{pH}$ values above 6 . Outside these ranges, strongly basic or strongly acidic exchangers should be used.

A protein above its pI (isoelectric point) will be positively charged and so will bind to a cation exchanger and not to an anion exchanger, and vice versa when the protein is below its pl. This technique has been used very effectively in the separation of proteins and bioactive peptides from cheese whey to create a new generation of high-value nutraceuticals and functional foods.

\subsection{Performance Parameters and Process Engineering of Chromatographic Systems}

The performance of a chromatographic separation is assessed by two parameters: resolution and throughput. Resolution is the counterpart to the rejection term in membrane separations. It measures how well a column containing a specific solid support under a given set of conditions separates the 
components of interest. Resolution $\left(R_{s}\right)$ is a function of three parameters: efficiency, selectivity and capacity, and is defined as:

$$
R_{S}=\frac{1}{4} \sqrt{N}\left(\frac{\alpha-1}{\alpha}\right)\left(\frac{K+1}{K}\right)
$$

where $\alpha$ is the selectivity, $K$ is the capacity and $N$ is the efficiency. These parameters are determined from a chromatogram as shown in Figure 10:

$$
R_{S}=\frac{2\left(V_{R 1}-V_{R 2}\right)}{V_{W 1}+V_{W 2}}
$$

The ideal value of $R_{S}$ is greater than 1 . A value of $R_{S}$ of 1.5 implies a perfect baseline separation.

Selectivity $(\alpha)$ is the measure of the ratio of relative retention of two components. It is a measure of how a column can differentially retain the compounds of interest. From a typical chromatogram shown in Figure 10:

$$
\alpha_{1 / 2}=\frac{V_{R 1}-V_{O}}{V_{R 2}-V_{O}}
$$

Capacity $(K)$ or retention is the measure of how strongly a solute interacts with the stationary phase. It is the ratio of moles of solute in the stationary phase to that in the mobile phase.

$$
K_{1}=\frac{V_{R 1}-V_{O}}{V_{O}}
$$

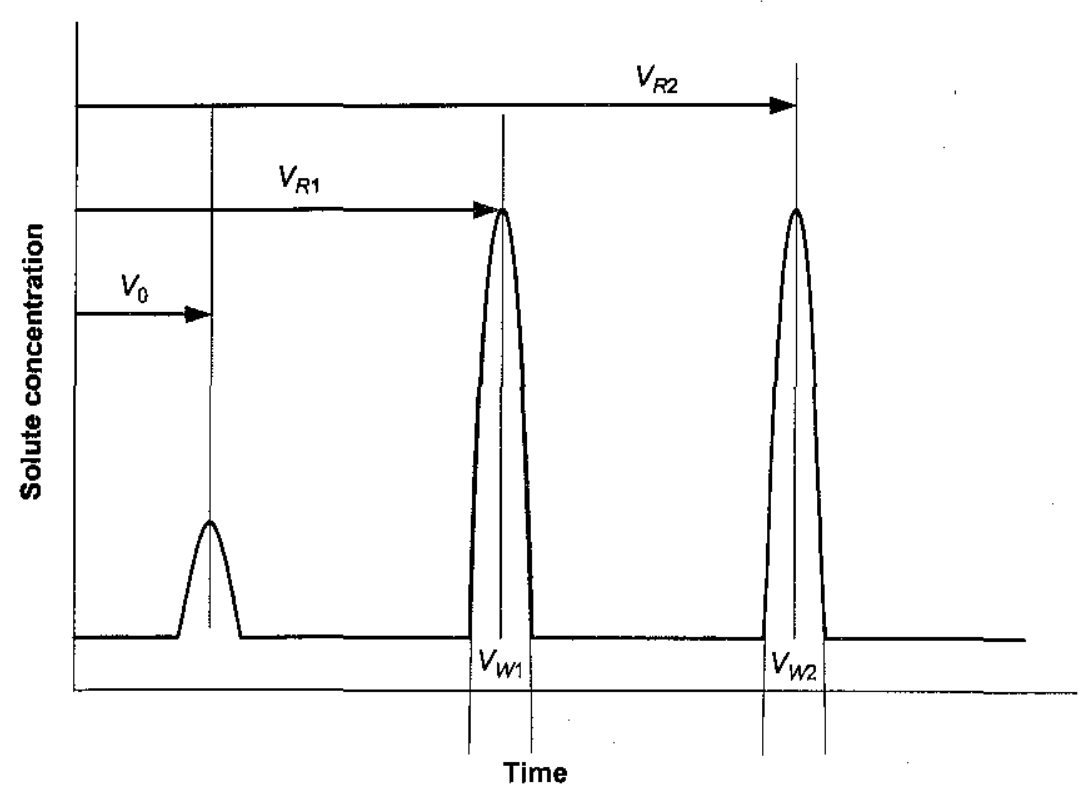

Figure 10 A typical chromatogram. $V$ is the retention volume. Subscripts $O, R_{1}$ and $R_{2}$ refer to the solvent and two compounds of interest. Subscripts $W_{1}$ and $W_{2}$ are peak widths 
Efficiency $(N)$ is expressed in terms of the number of plates in a column. It is the square of the ratio of twice the elution volume to the average peak width. It may be calculated from the chromatogram shown in Figure 10 as:

$$
N=16\left(\frac{V_{R}}{V_{W}}\right)^{2}
$$

The height equivalent to a theoretical plate (HETP) may be obtained as the ratio of length of the column $(L)$ to the number of plates in a column.

$$
H E T P=\frac{L}{N}
$$

The plate height represents how well a column has been packed. It may be obtained from the Van Deemters or Knox equation which take into account eddy diffusion, molecular diffusion and mass transfer resistance [9].

Throughput is analogous to the flux concept of membrane separations. It is the amount of purified product per unit bed volume. It is calculated as the product of utilized capacity, relative recovery and purity per unit time. The basic objective of any unit operation would be to maximize this parameter.

Some of the important factors influencing the resolution and throughput are the feed load, pressure, temperature, viscosity and particle size. The amount and concentration of feed in each run may be limited by the point at which the minimum desirable resolution is attained. Polymeric media may not resist high pressures. Hence the pressure at optimum throughput must be monitored. The pressure in a packed bed may also be calculated using the Blake-Kozeny-Carman equation [10].

Smaller particle size increases the resolution in the column but the pressure may increase to unacceptable levels. In addition, the media is more expensive [11]. If the particle size of the media is increased to reduce the pressures in the column, it will result in zone broadening and reduce resolution. The general procedure to optimize the flow rate is to do a pressure excursion on the column without exceeding the pressure limit for the media. The column is unpacked and packed again at $80 \%$ of the maximum flow rate obtained from the pressure excursion. Thus during the actual operation, the column would be operated at $80 \%$ of the flow rate and thus would not exceed $64 \%$ of the maximum pressure [12].

The effect of temperature depends on the nature of the retention in the column. In case of an exothermic retention, a decrease in temperature improves the resolution. Conversely, resolution improves with an increase in temperature for an endothermic retention. In case of an entropically driven process such as size exclusion chromatography, higher temperatures would speed up the process. However, polymeric media may have a temperature limitation. Even with ceramic media, the bound layer on the surface may not be stable above a certain temperature and may be eroded. If high viscosity of the eluent increases flow resistance unacceptably, either the temperature may be increased or viscosity modifiers may be added to the eluent.

One of the most significant limiting factors of column chromatography is irregular flow patterns during processing. Depending on how a column is packed, flow path and therefore, flow rates can vary in different parts of a column, resulting in fluid channeling or different absorption and desorption rates. A part of the column may be saturated with the target molecule, while other parts of the column may still have free binding sites, resulting in product binding and breakthrough occurring simultaneously, thus diminishing the resolving power of the column. Fluid channeling prevents proper resolution and this can result in product recovery failure. For gel- or resin-based chromatography, high pressures can lead to bed compaction, restricting flow rates and causing channeling, and ultimately poor resolution [13] 
Mathematical models describing the profile of a chromatographic process may be classified into 2 types:

(1) Macroscopic models: In macroscopic models, the distribution of the solute between mobile and stationary phases is described by one or more partial differential equations. Integrating these equations under initial and boundary conditions, assuming an isotherm model, gives the chromatogram. These models are most popular and may be further categorized into:

(a) Rate models, which directly integrate the differential mass balance equations for the system generally under several assumptions and lumped parameters. Numerical solutions to complete mass transfer equations have been given without any lumped parameters [14].

(b) Plate models, which the existence of several plates in the column with a distribution of solute between mobile and stationary phases in instantaneous equilibrium and a continuous mobile phase flow without any mixing in between the plates [15].

(2) Microscopic or statistical or stochastic models: These models assume the behavior of a single molecule in the chromatographic column as a random sequence of transfers between mobile and stationary phase. Probability laws determine the frequency and the length of the jumps, and the chromatographic peak is obtained when a large number of molecules are collected at the exit of the column. The most popular models in this category are Giddings-Eyring model $[16,17]$ and the Monte Carlo model [18].

\subsection{Chromatography Equipment}

Although continuous ion exchange and continuous chromatographic separations can be accomplished with essentially the same piece of equipment, the chemical processes are entirely different. The key difference is that the plate height is very small compared to conventional processes such as distillation. Separation may be accomplished using several different well defined configurations. Some of the main configurations are explained in the following sections:

(1) Single pass method. This system is essentially a scale up of the analytical method of chromatography. It uses one column and one loading followed by multicomponent fraction collection. It has low equipment costs, large flexibility and several degrees of freedom in changing eluents. An added advantage is that almost all components in the feed can be obtained with high purity, depending on the column selectivity. However, it has the least productivity and poor utilization of time and column media. The product is very dilute because of the large volume of eluent/desorbent needed.

(2) Circulation method. This is similar to the single pass method except that the mixed fraction is recycled back to the column. The target component can be recovered at a higher concentration compared to the single-pass mode due to the reduction in eluent needed.

(3) Moving bed. In this method, both media bed and eluent move in countercurrent directions. All the media is used very efficiently and throughput is high. However, the energy requirements are large compared to other configurations and there is the added risk of damaging the media during movement.

(4) Simulated moving bed (Sorbex system). This method was developed by UOP for the petrochemical industry. It is a continuous device well suited for large volume processing. Two fractions are obtained from the solution containing two or more components because of the differences in the rate at which they move through the solid phase. The system consists of 8 - 
16 beds and thus control becomes complicated with a high construction cost. It has to be automated for easy operation and control. Product purity is good and separation efficiency is high.

There have been several variations of this process that improved the efficiency and throughput still further, including the Improved Simulated Moving Bed (ISMB) and the Semi-continuous Countercurrent Chromatographic Refiners (SCCR).

\subsection{Fouling and Cleaning}

Typical foulants of chromatographic columns are the same four types as membranes: inorganic (salts, acids, bases), organic (proteins, lipids, polysaccharides, humectants), microbial (endotoxins, viruses) and colloidal. Chromatographic media may be especially badly fouled by some of these foulants and so all feed to the column is generally at least microfiltered.

Chromatographic media have more stringent restrictions on operating conditions. Hence, cleaning chemicals should be selected properly as well as the $\mathrm{pH}$ and temperature during cleaning has to be monitored carefully. One measure of cleaning efficiency is that the output signal should match the baseline, i.e., if the eluent is injected into the column, the chromatogram should be a flat line overlapping the earlier baseline.

\subsection{MEMBRANE CHROMATOGRAPHY}

Chromatography is the major, if not the only, method of final purification in the biotechnology and biopharmaceutical industries. On the other hand, a membrane is typically used before the chromatography column (for clarification) and after the column (for concentration), but generally not for fine separations. The strengths and weaknesses of membranes and chromatography are complimentary to each other. These are summarized and compared in Table 5. The two processes are also compared in Figure 11. With a membrane, the feed solution is pumped to the membrane unit which partitions the feed into two streams, the retentate and the permeate, in one operation. In chromatography, the feed solution is pumped into the inlet of a packed column which partitions the solutes into several different bands or zones within the unit. The products elute only in a second step when the eluent is pumped through after the feed. With a membrane, an additional operation called diafiltration can be used with fresh solvent to "wash" out impurities such as salts and other compounds below the size exclusion limit of the membrane, leaving behind a purified macromolecule. In chromatography, the purification is done as part of the main operation, although a separate step is needed for the elution of the bound components.

Since chromatography involves relatively high costs and low throughput, it became logical to consider combining it with the lower cost and higher throughput of membranes. This novel separation process, known as "membrane chromatography (MC)" was initially developed in the late 1980s and uses membranes as the solid (stationary) phase rather than solid particles. As shown in Figure 12, it basically consists of one or more individual membrane disks with the appropriate properties stacked on top of each other. The immediate advantage is that while the pores in a conventional solid support are usually dead-ended as shown in Figure 8, many of the pores in the membrane support are "through" pores and pass through the entire support, as shown in Figure 12.

This results in a major difference in the hydrodynamics of the intra-pore space. With conventional solid particles, interactions between the solutes to be separated and the active sites on the support 
Table 5 A comparison of membrane and chromatographic separation techniques

\begin{tabular}{|c|c|c|}
\hline & Column chromatography & Membrane separation \\
\hline \multirow[t]{6}{*}{$\begin{array}{l}\text { Separation } \\
\text { of solutes }\end{array}$} & Perfect separation & $\begin{array}{l}\text { Imperfect separation for MW differences } \\
<10 \text { times }\end{array}$ \\
\hline & Very high purity even at ppm levels & High purity requires diafiltration \\
\hline & $\begin{array}{l}\text { More than one pure component may be } \\
\text { obtained from a complex mixture in one step }\end{array}$ & $\begin{array}{l}\text { Limited to two fractions per membrane } \\
\text { operation }\end{array}$ \\
\hline & Slow process due to pore diffusion & Fast process due to convection mode \\
\hline & Dilute products & Concentrated product in retentate stream \\
\hline & Large volumes of eluents & Large volumes of diafiltration solvent \\
\hline \multirow[t]{4}{*}{ Equipment } & Large wide columns & Equipment size smaller for same throughputs \\
\hline & $\begin{array}{l}\text { Column packing and flow distribution } \\
\text { critical }\end{array}$ & $\begin{array}{l}\text { Important to minimize fouling and } \\
\text { concentration polarization }\end{array}$ \\
\hline & $\begin{array}{l}\text { Versatile due to variety of appropriate } \\
\text { chromatography media available for separation }\end{array}$ & $\begin{array}{l}\text { Large number of membranes available for } \\
\text { variety of separation operations }\end{array}$ \\
\hline & $\begin{array}{l}\text { Scale-up is a challenge. Restricted to } \\
\text { comparatively smaller process volumes }\end{array}$ & $\begin{array}{l}\text { Easy linear scalability, more amenable to } \\
\text { very large process volumes }\end{array}$ \\
\hline \multirow[t]{2}{*}{$\begin{array}{l}\text { Processing } \\
\text { factors }\end{array}$} & $\begin{array}{l}\text { High pressure drop leading to bed } \\
\text { consolidation and column blinding }\end{array}$ & $\begin{array}{l}\text { High velocities and short residence times } \\
\text { even at modest pressures }\end{array}$ \\
\hline & Low throughput & Very high throughput \\
\hline
\end{tabular}

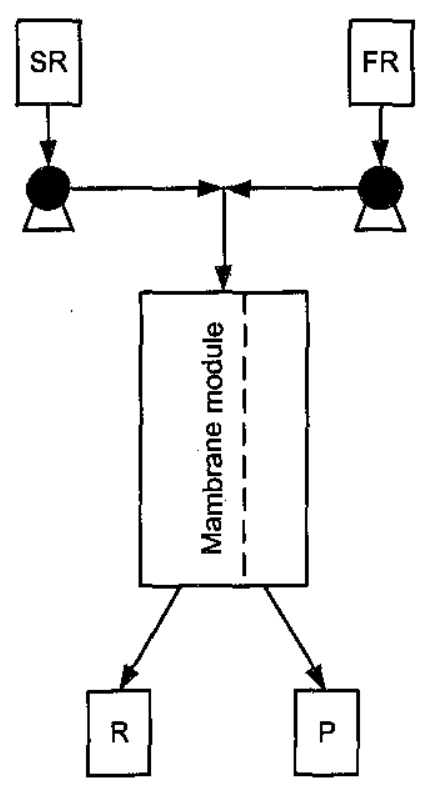

(a)

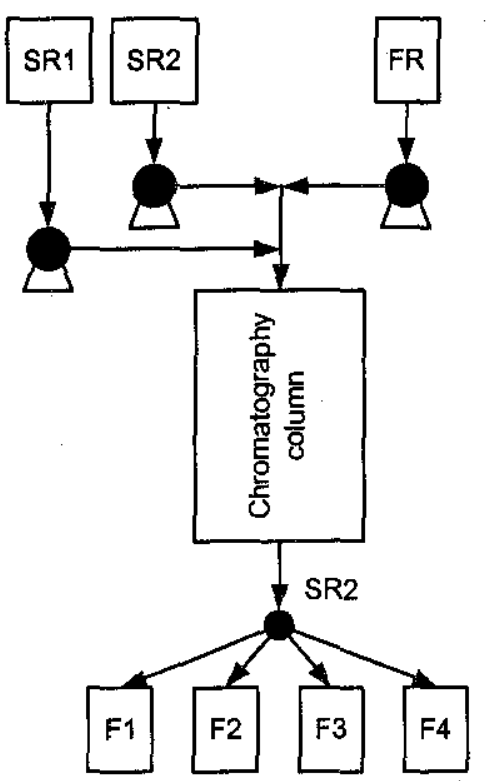

(b)

Figure 11 A schematic comparison of basic membrane and chromatography separations. (a) Membrane separations. SR - solvent reservoir for diafiltration; FR - feed reservoir; R-retentate; P-permeate. (b) Chromatography. SR-solvent reservoir; FR-feed reservoir; FDV - flow diversion valve; F- product fractions 

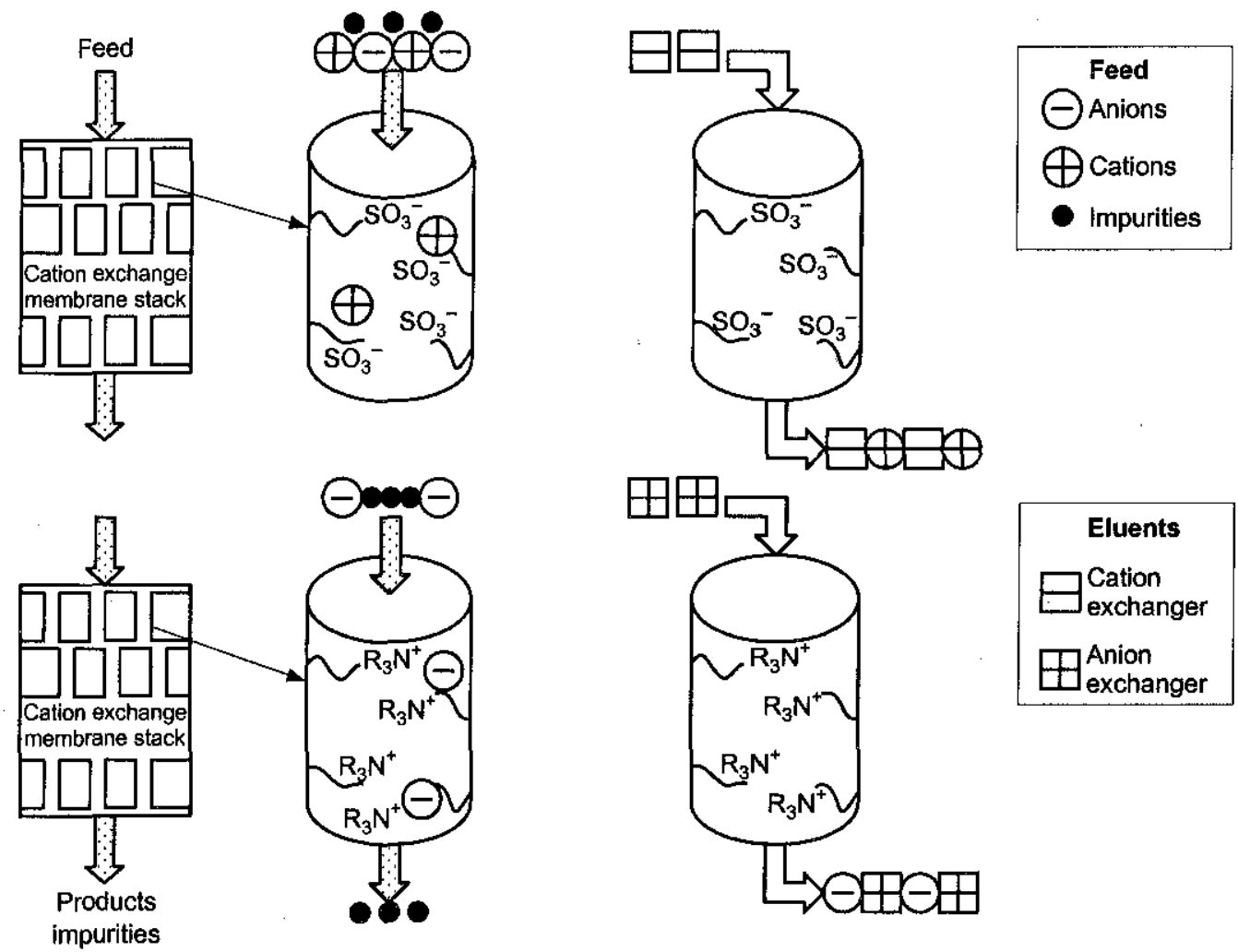

Figure 12 A typical membrane chromatography operation. A cation exchange membrane is followed by an anion exchange membrane to remove salts and impurities from a feed solution containing charged solutes

takes place under conditions where there is no flow of mobile phase. In fact, the stagnant intra-pore liquid can be considered to be part of the stationary phase. The solutes reach the active site only by molecular diffusion. As shown earlier in Figure 8, transport of the solute is limited by three phenomena: film diffusion due to the stagnant layer at the liquid-solid interphase, pore diffusion due to the transport of the solute to and from the active site on the support, and by the kinetics of the binding or interaction between the solute and the active site $[3,19]$. In contrast, the feed stream moves through membrane pores by convective flow with no by-pass of active sites as could occur with conventional and even "fast separation media" that have continuous through pores [20].

Thus the main resistances in MC are due to film diffusion and binding kinetics, which occur at much faster rates than pore diffusion. As a result, membranes are configured to form units that are shorter than traditional columns. In addition, because individual membranes are thin (about 1-3 mm), pressure drops in MC are much less than solid-particle columns for equivalent throughputs and binding capacities. This also means the thickness of a membrane stack (i.e., bed height) is not as critical as with resin bead chromatography.

The capture efficiency (dynamic capacity) is greater with membrane chromatography and is relatively independent of flow rate. Knudsen et al. [21] compared the effect of increasing the flow rate on breakthrough curves for solid-particle cation-exchange resins and ion-exchange membranes at equivalent residence times and sample loadings. For the columns, breakthrough occurred sooner, 
capacity decreased logarithmically and the shape of the breakthrough curves changed dramatically. With the membrane, however, the shape of the breakthrough curve was unchanged, the breakthrough point changed only slightly and capacity remained constant. They also observed an increase in binding capacity with the number of layers of membranes stacked on top of each other. This may be because with multiple layers, the effects of variations in pore sizes and thicknesses of individual membranes were minimized. In addition, high flow rates can be used which result in high axial Peclet numbers that minimized undesirable effects of axial diffusion [22]. Affinity membranes in particular can have higher throughputs of dilute feed solutions than packed bed columns that are limited by intrapore diffusion and pressure drops.

\subsection{Membrane Chromatography Materials and Equipment}

The same range of physicochemical interactions used in conventional chromatography is used in membrane chromatography: ion-exchange, affinity, hydrophobic interaction and reverse phase [19, 23-25]. The exception of course is size exclusion chromatography since membranes are inherently size exclusive. A membrane used in MC applications should have some necessary characteristics, such as: (a) The appropriate pore size, since the solute and sometimes the ligand could be macromolecules such as proteins. Microporous (microfiltration) membranes are preferred, with pore sizes from $0.2-2 \mu \mathrm{m}$, (b) Hydrophilicity, if separations are to be conducted in aqueous media, (c) Appropriate functional groups in the membrane pore to serve as active sites for binding or chemical activation for immobilizing ligands, (d) Neutral charge as far as possible to minimize non-specific binding by biomolecules, and (f) Mechanical, thermal and chemical stability [23].

The earliest commercial units were ion-exchange cellulose membranes stacked in a cartridge for protein separations [26]. Polysulfone has been used because of its chemical, thermal and biological stability. Polyamide membranes have been used after modification with hydroxymethyl cellulose to inhibit nonspecific binding of proteins [27]. PVDF membranes with a pore size of 0.2 microns and a thickness of $0.09 \mathrm{~mm}$ effectively separated monoclonal antibodies and ovine serum albumin at high salt concentrations using a gradient procedure [28]. The same membrane was used to separate lysozyme from chicken egg white using a high salt concentration to elute the bound lysozyme [29]. Composite membranes have also been produced, e.g., consisting of a support of cellulose and a surface of acrylic copolymer [30]. The Sepracor composite membrane was a blend of polyethersulfone (PES) and polyethylene oxide (PEO) coated with hydroxyethyl cellulose (HEC). The PES provides the physical strength and the HEC contains hydroxyl groups which can be activated for binding ligands $[23,31]$.

For affinity membrane applications, the membrane support has to be activated and then the ligand has to be coupled to the activated sites. Methods to accomplish these tasks are the same as for conventional affinity packed columns and have been reviewed by Kline [32] and Turkova [33], and specifically for membrane chromatography by Charcosset [23], Thommes and Kula [19] and Zeng and Ruckenstein [34].

Membranes can be wound into units similar to classic sterile filtration cartridges and capsules. For example, a 10-cm diameter, $75-\mathrm{cm}$ high membrane chromatography unit has a flow rate of $45 \mathrm{~L}$ / $\mathrm{min}$. To achieve a similar flow rate with a traditional packed column would require a 100 liter column. Both large and small membrane units have a direct correlation between flux and pressure, thus facilitating scale-up to batch sizes of 20,000 liters [35].

Typical membrane chromatography devices are shown in Figure 13. Almost all are laboratoryscale and available from manufacturers listed in Table 6. Most are single-use disposable units which may be more economical. This is because a resin-bead chromatography column must be cleaned, repacked, and its integrity validated, resulting in a significant amount of added expense for 

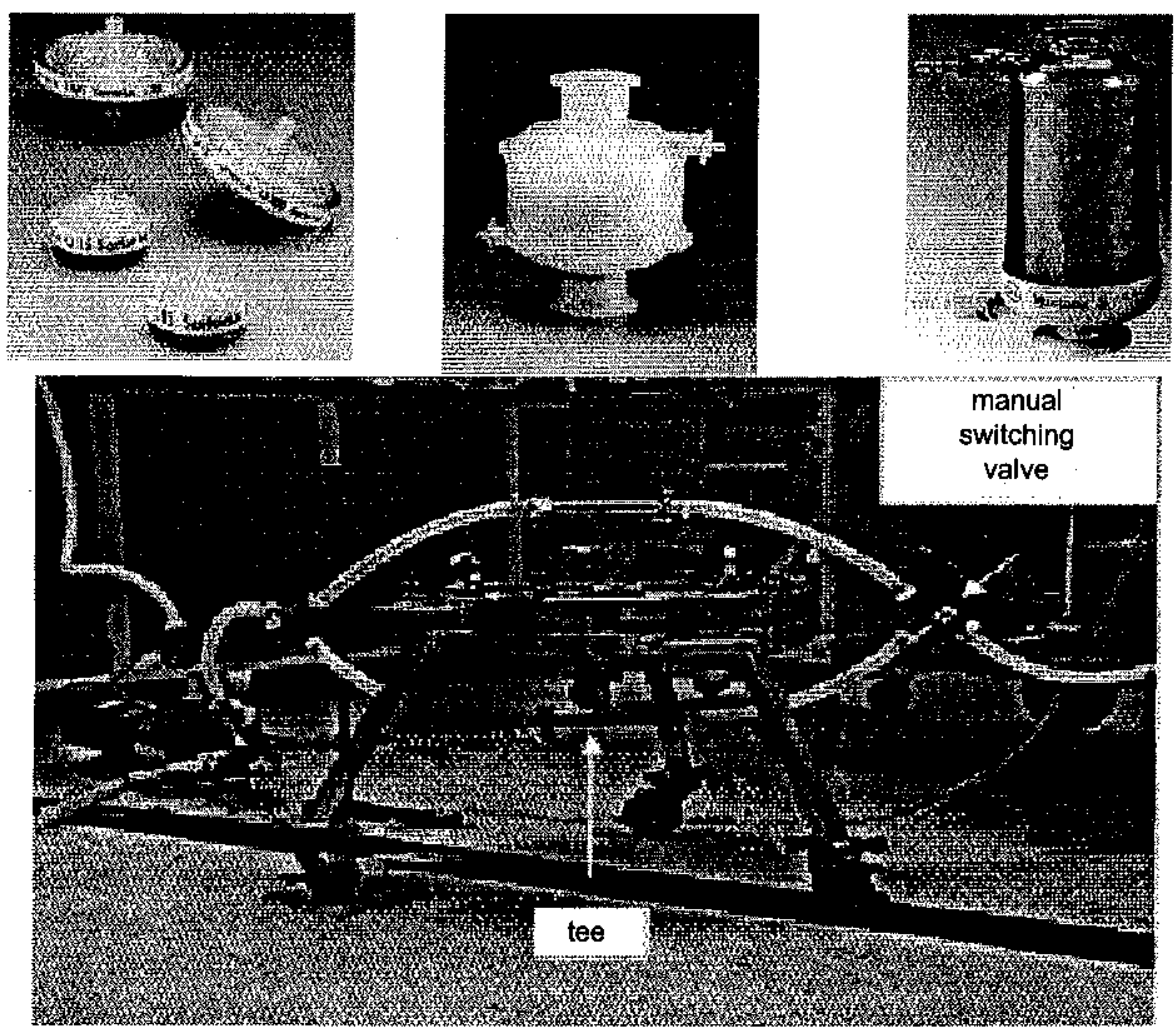

Figure 13 Typical commercial membrane chromatography devices. Top: Sartorius, Millipore, Pall; Bottom: Pall pilot scale unit

Table 6 Manufacturers of ion exchange membrane chromatography systems

\begin{tabular}{ll}
\hline \multicolumn{1}{c}{ Manufacturer } & \multicolumn{1}{c}{ Product } \\
\hline Pall & Mustang (flat sheet) \\
Millipore & Intercept $\mathrm{Q}$ (flat sheet) \\
Sartorius (Vivascience) & Sartobind,Vivapure, (flat sheet) \\
Saulentechnik & Quick disc (flat sheet) \\
CUNO & Radial flow cartridges \\
Kinetec System, Sepracor & Hollow fiber modules \\
\hline
\end{tabular}

maintenance, labor and time. On the other hand, disposable MC units can be precertified by their manufacturer for cleanliness, consistency and reliability. At the end of a purification cycle, the MC units can be simply discarded without the need to clean and conduct cleaning documentation.

Depending on the application, single-use chromatography could shorten the initial 100-200 days burden of process development required to validate cleaning. Another consideration is the savings of buffer used during cleaning and preparation procedures. Disposable units may reduce the buffer consumption by as much as $95 \%$. The possibility of cross-contamination between manufacturing 
lots is eliminated by the implementation of single-use systems. Units can also be autoclaved, giving manufacturers the ability to purify products under low bio-burden conditions [35].

Scale-up is a critical consideration for the biopharmaceutical industry. Merely increasing equipment size proportionally to increase capacity may not always produce expected results, especially with resin-bead chromatography columns. Retaining the same characteristics and performance during scale-up is challenging and expensive. In contrast, scale-up in membrane chromatography is a straightforward linear procedure because capacity is directly proportional to the membrane surface area (or volume) as well as to the size of the membrane unit (in which the bed height or number of membrane layers is held constant). Mass transport resistances in membrane chromatography are lower than conventional chromatography since pore diffusion is absent. Throughputs are also larger, about 100 times greater than columns, which means the volumes to be handled would not be enormous like chromatographic processes [19]. Thus membrane chromatography appears to be attractive in terms of materials cost and energy usage.

\subsection{Mathematical Models}

Figure 14 is a representation of an ideal pore in a membrane. A mathematical model that describes the process must include the effects of the driving force (i.e., the hydrodynamics in the pore) and the resistive forces (i.e., diffusive effects and binding kinetics). Diffusive effects are due to film diffusion when the solute moves through the boundary layer, and due to pore diffusion when the solute moves within the pore to the active site. Boundary layer resistance is much less compared to pore diffusion. Assuming no film resistance, a uniform radial concentration profile and a flat velocity profile, a continuity equation relating these parameters to the concentration of a solute at any time can be derived $[3,19,22]$ :

$$
\frac{\partial C_{i}}{\partial t}=D \frac{\partial^{2} C}{\partial z^{2}}-v \frac{\partial C_{i}}{\partial z}-\frac{2 \partial q}{r \partial t}
$$

where $C$ is the concentration of solute $i, D$ is the diffusion coefficient of the solute, $r$ is the pore radius, $v$ is the velocity of liquid in the pore, $z$ is the distance down the length of the pore, $q$ is the amount of solute adsorbed or bound to the active sites and $t$ is the time. The term on the left side of Equation (12) is for changes in solute concentration with time. The terms on the right side of Equation (12) are for changes in diffusive transport, convective transport and binding between solute and the active site in the pore, respectively (Figure 14). In membrane chromatography where pore diffusion is non-existent, the dimensionless Peclet number $(P e)$ has been introduced into the diffusive term. $P e$ is the ratio of convective transport to diffusive transport or it can be considered as the ratio of diffusion time $\left(t_{D}\right)$ to residence time $\left(t_{P}\right)$ in the pore [36]:

$$
P e=\frac{v L_{P}}{D}+\frac{L_{P}^{2} / D}{L_{P} / v}=\frac{t_{D}}{t_{P}}
$$

where $L_{P}$ is the length of the membrane pore. The diffusive term now is $(1 / P e)\left(\partial^{2} C / \partial z^{2}\right)$.

The usefulness of these models has been studied for a BSA-monoclonal antibody affinity membrane chromatography application by Suen and Etzel [22]. They showed that there were little or no axial diffusion effects when $P e>40$ or if the membrane thickness was $>265 \mu \mathrm{m}$. Frey et al. [37] observed an increase in HETP with $P e$ which showed that axial dispersion is much more important in bandbroadening than pore and film diffusion. Similar results were reported by Nachmann et al. $[38,39]$ for hollow fiber membranes. They showed that, when $P e>42$, binding kinetics was essentially the 


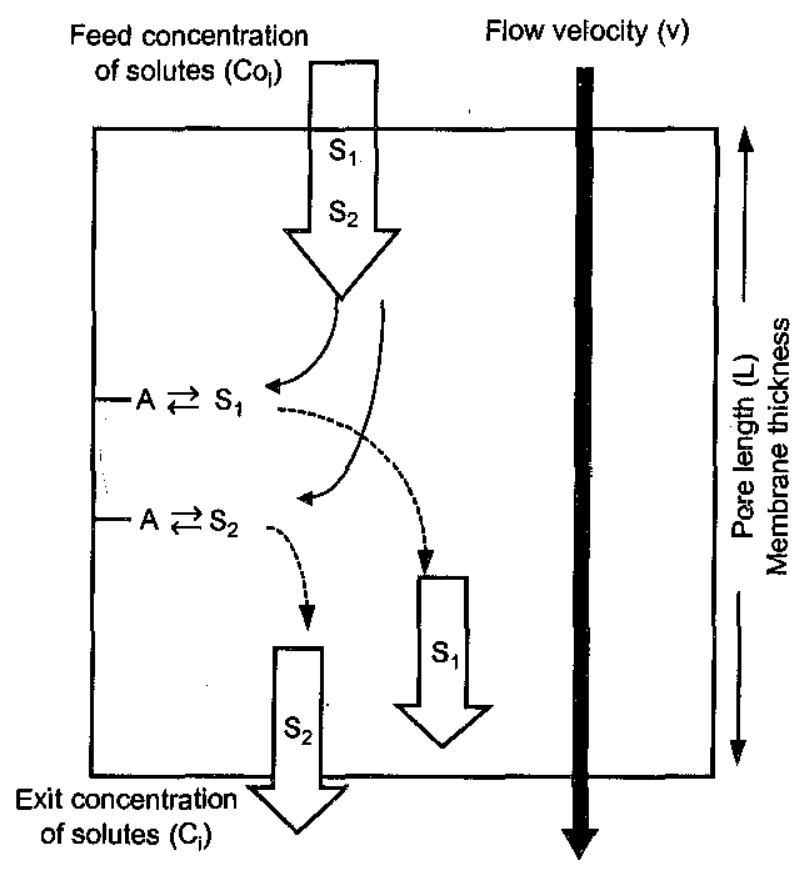

Figure 14 Schematic representation of a pore in membrane chromatography. A feed solution containing solutes $S_{1}$ and $S_{2}$ at concentrations of $\mathrm{Co}_{\mathrm{i}}$ flows through the pore at a velocity (v). The individual solutes interact to different extents with the active sites (A) on the inside surface of the pore. The solutes have a concentration of $\mathrm{C}_{\mathrm{i}}$ at any time or distance within the pore

sole rate-controlling phenomenon in antigen-antibody affinity systems. Liu and Fried [40] also introduced a radial Peclet Number to account for radial dispersion effects in a lysozyme-Cibacron blue affinity membrane system. Both radial and axial dispersion effects could be neglected when the radial $P e$ wasless than 0.04 and axial $P e$ was above 25. In general, diffusion times in pores have been estimated to be much less than fluid residence times in the pore $[8,19,22,28,29,36]$. This confirms the validity of the assumption that axial effects could be neglected and that there was sufficient time for solutes to diffuse to the pore wall for separation to occur.

The issue of concentration polarization has not been specifically considered in membrane chromatography. With membrane separations, the formation of a dynamic gel-like layer of large solutes and/or colloidal particles on the membrane surface ("concentration polarization") results in a significant decrease in flux either due to the hydrodynamic resistance of the boundary layer or due to an increase in the osmotic pressure. Above a certain feed concentration, the solute may precipitate out and foul the membrane [1]. This issue is even more important in membrane chromatography since concentration polarization would cause a the loss of activity of the chromatographic medium. Hence, it is important to clarify the feed stream by microfiltration or ultrafiltration to remove large insoluble particles or macromolecules (other than the protein of interest) prior to membrane chromatography. In addition, processing parameters such as pressure drop should be carefully monitored during the operation. 


\subsection{APPLICATIONS}

Some of the major industrial applications of membranes and chromatography processes are summarized in Tables 7 and 8. Membranes are usually used for fractionation and concentration whereas chromatography is used for purification and isolation of specific compounds. Since almost

Table 7 Commercial applications of membrane technology

\begin{tabular}{|c|c|}
\hline Industry & Application \\
\hline Biotechnology & $\begin{array}{l}\text { - Production of high quality water } \\
\text { - Clarification and concentration of proteins and enzymes } \\
\text { - In membrane bioreactors for enzyme hydrolysis, tissue culture } \\
\text { - Viruses, bacteria, pyrogens, removal }\end{array}$ \\
\hline Pharmaceuticals & $\begin{array}{l}\text { - Separation and purification of antibiotics } \\
\text { - Recovery of organic solvents }\end{array}$ \\
\hline Nutraceuticals & - Separation and concentration of xanthophylls from corn extract \\
\hline Sugar & $\begin{array}{l}\text { - Clarification of sweeteners } \\
\text { - Recovery of starches } \\
\text { - Clarification, desalting and preconcentration of sucrose extracts }\end{array}$ \\
\hline Dairy & $\begin{array}{l}\text { - Clarification, concentration or demineralization of milk and whey } \\
\text { - Fractionation of milk and whey to high value fractions } \\
\text { - Defatting and reducing microbial load }\end{array}$ \\
\hline Food processing & $\begin{array}{l}\text { - Concentration of egg and egg white } \\
\text { - Clarification of wine, juice and vinegar } \\
\text { Oil degumming and refining }\end{array}$ \\
\hline Water and waste treatment & - Waste water treatment from almost all the industries \\
\hline
\end{tabular}

Table 8 Commercial applications of chromatographic separations

\begin{tabular}{|c|c|}
\hline Industry & Application \\
\hline Biotechnology & $\begin{array}{l}\text { - Separation and purification of nucleic acids, enzymes, amino acids and } \\
\text { - Reptides } \\
\text { - Reversed phase chromatography for interleukins, recombinant protein/ } \\
\text { - Size-exclusion chromatography for viruses } \\
\text { - Fractionation of human plasma proteins }\end{array}$ \\
\hline Pharmaceuticals & - Separation and purification of antibiotics \\
\hline Nutraceuticals & $\begin{array}{l}\text { - Isolation of isoflavones from soybeans } \\
\text { - Separation and purification of vitamins }\end{array}$ \\
\hline Sugar & $\begin{array}{l}\text { - Separation of sucrose/oligosaccharide, maltose/glucose, oligosaccharide/ } \\
\text { dextrin, sucrose/fructose } \\
\text { - Desalting molasses }\end{array}$ \\
\hline Dairy & $\begin{array}{l}\text { - Fractionation of cheese whey into whey protein isolate, alphalactalbumin, } \\
\text { lactoferrin and CGMP for use in infant formulae, performance foods and } \\
\text { other functional foods }\end{array}$ \\
\hline Food processing & $\begin{array}{l}\text { - To debitter and deacidify citrus juice } \\
\text { - Purification and refining of food extracts }\end{array}$ \\
\hline Water treatment & $\begin{array}{l}\text { - Recovery of valuable products from the waste water with a simultaneous } \\
\text { production of high quality process water }\end{array}$ \\
\hline
\end{tabular}


all commercially available equipment for membrane chromatography is presently mostly ion exchange membranes, much of the work to date has been done on the purification/separation of large molecules like DNA plasmids and endotoxins. Other potential applications include purification of protein mixtures and peptides at high throughput rates.

Anion exchange membrane chromatography has been used for the separation of protein complexes in milk, bovine serum albumin, ovalbumin and myoglobulin, enzymes such as photodiesterase, lysosyme and $\beta$ galactosidase (Table 9). Cation exchange membrane chromatography has been used to separate complex mixtures like hemoglobin from. blood, enzymes and monoclonal antibodies. Table 10 summarizes these applications and the membranes utilized.

Some experiments have also been done utilizing the advantage of having both cation exchange and anion exchange membranes in the same module. Some of the application tested and the membranes used are summarized in Table 11.

Table 9 Applications of anion-exchange membrane chromatography

\begin{tabular}{|c|c|c|c|c|}
\hline $\begin{array}{l}\text { Membrane } \\
\text { configuration }\end{array}$ & $\begin{array}{l}\text { Membrane } \\
\text { manufacturer }\end{array}$ & Product & Substances isolated & Reference \\
\hline \multirow[t]{6}{*}{ Flat sheet } & Satorius & Sartobind Q & Lysozyme, BSA & Gebauer et al. [41] \\
\hline & & MA Q15, 100,15 & Milk proteins & Splitt et al. [42] \\
\hline & Millipore & DEAE Memsep 100 & Ovalbumin, myogiobin & Shiosaki et al. [43] \\
\hline & & DEAE Memsep & Photodiesterase & Prpic et al. [44] \\
\hline & & DEAE Memsep 1000 & FDH & $\begin{array}{l}\text { Krupenko and } \\
\text { Wagner [45] }\end{array}$ \\
\hline & Saulentechnik & Quick disc Q & $\begin{array}{l}\text { Human tumor necrosis } \\
\text { factor }\end{array}$ & Luksa et al. [46] \\
\hline \multirow[t]{2}{*}{ Hollow fiber } & Kinetek & Microisonet $1100 \mathrm{D}$ & $\beta$ Galactosidase & Heng and Glatz [47] \\
\hline & Non-commercial & PEI on CA & BSA & Chen et al. [48] \\
\hline
\end{tabular}

Table 10 Applications of cation-exchange membrane chromatography

\begin{tabular}{lllll}
\hline $\begin{array}{l}\text { Membrane } \\
\text { configuration }\end{array}$ & $\begin{array}{l}\text { Membrane } \\
\text { manufacturer }\end{array}$ & \multicolumn{1}{c}{ Product } & \multicolumn{1}{c}{ Substances isolated } & \multicolumn{1}{c}{ Reference } \\
\hline Flat sheet & Satorius & Sartobind S & Haemoglobin, Lysozyme & $\begin{array}{l}\text { Demmer and } \\
\text { Nussbaumer [49] }\end{array}$ \\
& & & Immunoglobulin & $\begin{array}{l}\text { Langlotz and Kroner } \\
\text { [50] }\end{array}$ \\
& Millipore & CM Memsep 1010 & $\begin{array}{l}\text { Immunotoxin, } \\
\text { monoclonal antibody }\end{array}$ & Dosio et al. [51] \\
& Saulentechnik & Quickdisc C4 & $\begin{array}{l}\text { Human tumor necrosis } \\
\text { factor } \\
\text { Lysozyme } \\
\text { Non commercial }\end{array}$ & $\begin{array}{l}\text { Warner and Kostel } \\
\text { [35] }\end{array}$ \\
& $\begin{array}{l}\text { PEI on CA } \\
\text { DEA and EA on PE } \\
\text { (from Asahi) }\end{array}$ & Shinano et al. [52] \\
& & & Tsuneda et al. [53] \\
\hline
\end{tabular}


Table 11 Applications of membrane chromatography with a combination of anion-and cation-exchange membranes

\begin{tabular}{|c|c|c|c|c|}
\hline $\begin{array}{l}\text { Membrane } \\
\text { configuration }\end{array}$ & $\begin{array}{l}\text { Membrane } \\
\text { manufacturer }\end{array}$ & Product & Substances isolated & Reference \\
\hline \multirow[t]{8}{*}{ Flat sheet } & Satorius & Sartobind $\mathrm{Q}, \mathrm{S}$ & $\begin{array}{l}\text { Lysozyme, Ovalbumin, } \\
\text { BSA, IgM }\end{array}$ & Santarelli et al. [54] \\
\hline & & & Plasma proteins & Gebauer et al. [55] \\
\hline & & & Immunoglobulin & Knudsen et al. [21] \\
\hline & & & $\begin{array}{l}\text { Lysozyme, chymotripsinogen, } \\
\text { soybean trypsin inhibitor }\end{array}$ & Reif and Freitag [56] \\
\hline & Millipore & Memsep 1010 & $\begin{array}{l}\text { Lysozyme, chymotripsinogen, } \\
\text { cytochrom c, lacalbumin, } \\
\text { conalbumin, ovalbumin }\end{array}$ & Freitag et al. [57] \\
\hline & Whatman & P81 & Lysozyme, BSA, globulin & Lin and Suen [58] \\
\hline & & DE 81 & Egg white & $\begin{array}{l}\text { Manganaro and } \\
\text { Goldberg [59] }\end{array}$ \\
\hline & Non commercial & Lewatit resin & BSA, bovine haemoglobin & Avramescu et al. [60] \\
\hline Radial flow & Millipore & Zetaprep 100 & Human albumin & Bourgeacq et al. [61] \\
\hline
\end{tabular}

\subsection{CONCLUSIONS}

Membrane chromatography combines the high throughput advantages of membrane systems and the selectivity of chromatography to create an efficient separation method. Protein separations can occur at 10-200 times the rate of packed columns. Adsorptive membranes have binding capacities as high as packed columns, yet proteins can be concentrated by 10 -fold or more with recoveries of $85-100 \%$ [23]. Cycle times are of the order of minutes compared to hours with packed columns. However, although the principles and advantages of membrane chromatography have been demonstrated by numerous published studies, there are very few commercial applications on a significant scale today. With the number and variety of applications increasing, this situation can be expected to change, especially with the development of improved membranes with higher capacity and better flow distributions in the modules.

\section{REFERENCES}

[1] Cheryan, M. 1998. Ultrafiltration and Microfiltration Handbook. Boca Raton, FL: CRC Press.

[2] Cheryan, M., and D. J. Nichols, 1992. Modeling of Membrane Processes. In Mathematical Modeling of Food Processing Operations. S. Thorne (Ed.). London: Elsevier Publications:

[3] Suen, S., M. Caracotsios, and M. R. Etzel. 1993. Sorption Kinetics and Axial Diffusion in Binary-Solute Affinity-membrane Bioseparations. Chem. Eng. Sci. 48(10): 1801-1812.

[4] Roos, P. H. 2000. Ion Exchange Chromatography. In Protein Liquid Chromatography. M. Kastner (Ed.). Journal of Chromatography Library. Amsterdam: Elsevier Science. 61: 5-9.

[5] Desai, M.A. 2000. Downstream Processing of Proteins. Totawa, NJ: Humana Press.

[6] Montesinos, R. M., A. Tejeda-Manisr, R. Guzmin, J. Ortega, and W. E. Schiesser. 2005. Analysis and Simulation of Frontal Chromatography of Proteins. Sep. Purif. Technol. 42: 75-84.

[7] Grunwald, A. G., and M. S. Shields. 2001. Plasmid Purification Using Membrane-based Anionexchange Chromatography. Anal. Biochem. 296: 1- 4. 
[8] Kochan, J., Y. Wu, and M. Etzel. 1996. Purification of Bovine Immunoglobulin G via Protein G Affinity Membranes. Ind. Eng. Chem. Res. 35: 1150-1155.

[9] Knox, J. H. 2002. Band Dispersion in Chromatography - A Universal Expression for the Contribution from the Mobile Zone. J. Chromatography A. 960: 7-18.

[10] McCabe, W., J. Smith, and P. Harriot. 2000. Unit Operations of Chemical Engineering. NY: McGraw Hill.

[11] Ladisch, M. R. 2001. Bioseparations Engineering: Principles, Practice and Economics. New York: Wiley Interscience.

[12] Sofer, G. K., and L. E. Nystrom. 1991. Process Chromatography: A Guide to Validation. London: Academic Press.

[13] Pendlebury, D. 2003. New Innovations in Membrane Chromatography. http://www.a2c2.com/ articles. asp?pid $=357$.

[14] Frey, G. L., and E. Grushka. 1996. Numerical Solution of Complete Mass Balance Equation in Chromatography. Anal. Chem. 62: 189-200.

[15] Velayudhan, A., and M. Ladisch. 1993. Plate Models in Chromatography: Analysis and Implications for Scale-up. In Chromatography. G.T. Tsao (ed.). Berlin: Springer Verlag. 123145.

[16] Giddings, J. C., and H. Eyeing. 1955. A Molecular Dynamic Theory of Chromatography. J. Phys. Chem. 59: 416-421.

[17] Giddings, J. C. 1963. Plate Height of Non-uniform Chromatographic Columns. Gas Compression Effects, Coupled Columns and Analogous Systems. Anal. Chem. 35: 353-356.

[18] Cavazzini, A., F. Dondi, A. Jaulmes, C. Vidal-Madjar, and A. Felinger. 2002. Monte Carlo Model of Nonlinear Chromatography: Correspondence Between the Microscopic Stochastic Model and the Macroscopic Thomas Kinetic Model. Anal. Chem. 74: 6269-6278.

[19] Thommes, J., and M. R. Kula. 1995. Membrane Chromatography - An Integrative Concept in the Downstream Processing of Proteins. Biotechnol. Progr. 11:357-367.

[20] Podgornik, A., and T. B. Tennikova. 2002. Chromatographic Reactors Based on Biological activity. In Advances In Biochemical Engineering Biotechnology. Berlin: Springer-Verlag. 76: 174.

[21] Knudsen, H. L., R. L. Fahrner, Y. Xu, L. A. Norling, and G. S. Blank. 2001. Membrane Ionexchange Chromatography for Process-scale Antibody Purification.J. Chromatography A. 907: $145-154$.

[22] Suen, S., and M. R. Etzel. 1992. Mathematical Analysis of Affinity Membrane Bioseparations. Chem. Eng. Sci. 47: 1355-1364.

[23] Charcosset, C. 1998. Purification of Proteins by Membrane Chromatography. J. Chemical Technol. Biotechnol. 71(2): 95-110.

[24] Josic, D., and A. Strancar. 1999. Application of Membranes and Compact, Porous Units for the Separation of Biopolymers. Ind. Eng .Chem. Res. 38: 333-342.

[25] Tennikova, T. B., M. Nahunek, and F. Svec. 1991. Modified Macroporous Copolymers of Glycidyl Methacrylate with Ethylene Dimethacrylate as Sorbents for Ion-exchange and Hydrophobic Interaction Chromatography. J. Liquid Chromatography. 14: 2621-2632.

[26] Tennikova, T. B., and F. Svec. 1993. High-performance Membrane Chromatography: Highly Efficient Separation Method for Proteins in Ion-exchange, Hydrophobic Interaction and Reversed-phase Modes. J. Chromatography. 646: 279-288.

[27] Beeskow, T. C., W. Kusharyoto, F. B. Anspach, K. H. Kroner, and W. D. Deckwer. 1995. Surface Modification of Microporous Polyamide Membranes with Hydroxyethyl Cellulose and Their Application as Affinity Membranes. J. Chromatography A. 715: 49-65.

[28] Ghosh, R. 2001. Separation of Proteins Using Hydrophobic Interaction Chromatography. J. Chromatography 923: 59-64. 
[29] Ghosh, R. 2003. Purification of Lysozyme by Microporous PVDF Membrane-based Chromatographic Process. Biochem. Eng. J. 14: 109-116.

[30] Huo, K. C., R. Zaniewski, and S. Roy. 1991. Protein a Immobilized Affinity Cartridge for Immunoglobulin Purification. Biotechnol. Appl. Biochem. 13: 257-268.

[31] Klein, E., E. Eichholz, and D. Yeager. 1994. Affinity Membranes Prepared from Hydrophilic Coatings on Microporous Polysulfone Hollow Fibers. J. Membrane Sci. 90: 69-80.

[32] Kline, T. 1993. Handbook of Affinity Chromatography. New York: Marcel Dekker.

[33] Turkova, J. 1993. Bioaffinity Chromatography. Amsterdam: Elsevier Science. 31-32.

[34] Zeng, X., and E. Ruckenstein. 1999. Membrane Chromatography: Preparation and Applications to protein Separation. Biotechnol. Progr. 15: 1003-1019.

[35] Warner, T., and P. Kostel. 2000. Disposable Mustang Q Capsules and Cartridges. Genetic Engineering News. 28(19): 1-3.

[36] Klein, E. 1991. Affinity Membranes: Their Chemistry and Performance in Adsorptive Separation Processes. New York: Wiley. 131-140.

[37] Frey, D. D., R. Van de Water, and B. Zhang. 1992. Dispersion in Stacked-membrane Chromatography. J. Chromatography. 603: 43-47.

[38] Nachmann, A., A. R. M. Azad, and P. Bailon. 1992a. Membrane-based Receptor Affinity Chromatography. J. Chromatography. 597: 155-166.

[39] Nachmann, A., A. R. M. Azad, and P. Bailon. 1992b. Efficient Recovery of Recombinant Proteins Using Membrane-based Immunoaffinity Chromatography (MIC). Biotechnol. Bioeng. 40: 564571.

[40] Liu, C. H., and J. R. Fried. 1994. Breakthrough of Lysozyme Through an Affinity Membrane of Cellulose-Cibacron Blue 3GA. AIChE Journal. 40: 40-49.

[41] Gebauer, K. H., J. Thommes, and M. R. Kula. 1997. Plasma Protein Fractionation with Advanced Membrane Adsorbents. Biotechnol. Bioeng. 54: 181-189.

[42] Splitt, H., I. Mackenstedt, and R. Freitag. 1996. Preparative Membrane Adsorber Chromatography for the Isolation of Cow Milk Components. J. Chromatography A. 729: 8797.

[43] Shiosaki, A., M. Goto, and T. Hirose. 1994. Frontal Analysis of Protein Adsorption on a Membrane Adsorber. J. Chromatography A. 679: 1-9.

[44] Prpic, V., R. J. Uhing, and T. W. Gettys. 1993. Separation and Assay of Phosphodiesterase Isoforms in Murine Peritoneal Macrophages Using Membrane Matrix DEAE Chromatography and $\left[{ }^{32}\right.$ P]cAMP. Anal. Biochem. 208: 155-160.

[45] Krupenko, S. A., and C. Wagner. 1998. Over-expression of Functional Hydrolase Domain of Rat Liver 10-formyltetrahydrofolate Dehydrogenase in Escherichia coli. Protein Expression Purif. 14: 146-152.

[46] Luksa, J., V. Menart. S. Milicic, B. Kus, V. Gaberc-Porekar, and D. Josic. 1994. Ionic Crosslinking of $\mathrm{SO}_{3} \mathrm{H}^{-}$Group Containing Graft Chains Helps to Capture Lysozyme in a Permeation Mode. J. Chromatography A. 661: 161-168.

[47] Heng, M. H., and C. E. Glatz. 1993. Charged Fusions for Selective Recovery of $\beta$-galactosidase from Cell Extract Using Hollow Fiber Ion-exchange Membrane Adsorption. Biotechnol. Bioeng. 42: 333-338.

[48] Chen, Z., M. Deng, Y. Chen, G. He, M. Wu, and J. Wang. 2004. Preparation and Performance of Cellulose Acetate/polyethyleneimine Blend Microfiltration Membranes and Their Applications. J. Membrane Sci. 235: 73-86.

[49] Demmer, W., and D. Nussbaumer. 1999. Large-scale Membrane Adsorbers. J. Chromatography A. 852: 73-81.

[50] Langlotz, P., and K. H. Kroner. 1992. Surface-modified Membranes as a Matrix for Protein Purification. J. Chromatography A. 591: 107-113. 
[51] Dosio, F., S. Arpicco, S. Canevari, M. Figini, and D. Gastaldi. 1999. Single-step Purification of Immunotoxins Containing a High Ionic Charge Ribosome Inactivating Protein Clavin by Carboxymethyl High-performance Membrane Chromatography. J. Chromatography A. 830: 329-335.

[52] Shinano, H., S. Tsuneda, K. Saito, S. Furusaki, and T. Sugo. 1993. Ion Exchange of Lysozyme during Permeation Across a Microporous Sulfopropyl-group-containing Hollow Fiber. Biotechnol. Progr. 9: 193-198.

[53] Tsuneda, S., H. Shinano, K. Saito, S. Furusaki, and T. Sugo. 1993. Binding of Lysozyme onto a Cation-Exchange Microporous Membrane Containing Tentacle-type Grafted Polymer Branches. Biotechnol. Progr. 10: 76-81.

[54] Santarelli, X., F. Domergue, G. Clofent-Sanchez, M. Dabadie, R. Grissely, and C. Coassignee. 1998. Characterization and Application of New Macroporous Membrane Ion Exchangers. J. Chromatography B. 706: 13-22.

[55] Gebauer, K. H., J. Thommes, J., and M. R. Kula. 1998. Breakthrough Performance of Highcapacity Membrane Adsorbers in Protein Chromatography. Chem. Eng. Sci. 52: 405-419.

[56] Reif, O. W., and R. Freitag. 1993. Characterization and Application of Strong Ion-exchange Membrane Adsorbers as Stationary Phases in High-performance Liquid Chromatography of Proteins. J. Chromatography A. 654: 29-41.

[57] Freitag, R., H. Splitt, and O. W. Reif. 1996. Controlled Mixed-mode Interaction Chromatography on Membrane Adsorbers. J. Chromatography A. 728: 129-137.

[58] Lin, S., and S. Suen, S. 2002. Protein Separation Using Plate-and-frame Modules with Ionexchange Membranes. J. Membrane Sci. 204: 37-51.

[59] Manganaro, J. L., and B. S. Goldberg. 1993. Protein Purification with Novel Porous Sheets Containing Derivatized Cellulose. Biotechnol. Progr. 9: 285 - 290.

[60] Avramescu, M., Z. Borneman, and M. Wessling. 2003. Mixed-matrix Membrane Adsorbers for Protein Separation. J. Chromatography A. 1006: 171-183.

[61] Bourgeacq, J. F. L., C. Desneux, and M. A. Allary. 1991. A New Procedure Using Membrane Chromatography for the Valorization of Fraction IV from Kistler and Nitschmann's Fractionation of Blood Plasma. Chromatographia. 32: 27-32. 